\title{
Liberalização da Conta de Capitais e Inflação: A Experiência Brasileira no Período Pós-Real ${ }^{+}$
}

\author{
- Helder Ferreira de Mendonça *
}

- Manoel Carlos de Castro Pires**

\section{RESUMO}

Nos anos 1990 desenvolveu-se a idéia de que a liberalização da conta de capitais seria capaz de disciplinar a condução da política monetária para a busca da estabilidade de preços. Com base neste argumento é feito um desenvolvimento para o modelo Gruben e McLeod (200I) por meio da inclusão da dinâmica da dívida pública como uma restrição à função utilidade da autoridade monetária. Ademais, é feita uma análise empírica para o caso brasileiro no período posterior à introdução do Plano Real (por meio da aplicação de VAR) com o objetivo de avaliar se o aumento da liberalização da conta de capitais contribuiu para a estabilidade de preços. Os resultados encontrados sugerem que uma redução na liberalização da conta de capitais é capaz de atenuar a pressão inflacionária e que a duração deste efeito depende do regime de câmbio em vigor.

\section{PALAVRAS-CHAVE}

inflação, liberalização financeira, credibilidade

\begin{abstract}
In the 1990s the idea that capital account liberalization represented a mechanism for disciplining the conduction of the monetary policy in the search for price stability was developed. Based on this argument, a new version of Gruben e McLeod's (200I) model applying a dynamic public debt constraint to the monetary authority's utility function is made. Furthermore, an empirical analysis (through application of VAR) was made for the Brazilian case with the objective of evaluating if the increase in the capital account liberalization after the introduction of the Real Plan contributed to price stability. The findings denote that a decrease in the capital account liberalization is capable of attenuating inflationary pressure and that the duration of this effect depends on the exchange regime used.
\end{abstract}

\section{KEY WORDS}

inflation, capital account liberalization, credibility

\section{JEL ClASSIFICATION \\ E3I, E63}

\footnotetext{
+ Os autores agradecem às sugestões feitas por Flávio Vilela Vieira e Michele Polline Veríssimo a uma versão anterior que deu origem a este trabalho. Agradecemos, ainda, aos profícuos comentários realizados por dois pareceristas anônimos. Como de praxe, as possíveis omissões ou imprecisões são de inteira responsabilidade dos autores.

* Professor do Departamento de Economia da UFF e Pesquisador do CNPq. E-mail: helderfm@hotmail.com. Endereço para contato: Rua Dr. Sodré, 59 - Vila Suíça - Miguel Pereira - RJ. CEP: 26900-000.

* Da Coordenação de Finanças Públicas (CFP) do IPEA e Doutorando em Economia da UnB. E-mail: manoel.pires@ipea.gov.br. Endereço para contato: SQS 212 bloco D apto 216 - Asa Sul - Brasília - DF. Cep: 70275-040.

(Recebido em junho de 2004. Aceito para publicação em abril de 2005).
} 


\section{INTRODUÇÃO}

O trilema da economia aberta ou trindade inconsistente, um resultado sumariado por Obstfeld e Taylor (1998) a partir do modelo Mundell-Fleming, afirma que a conjugação de três condições - a mobilidade de capitais, o câmbio fixo, e a autonomia para realizar políticas monetárias independentes - não representa uma combinação factível para o mundo real. Neste sentido, uma das condições supracitadas deve ser abandonada para que as outras duas possam vigorar. Durante o sistema de Bretton Woods a opção encontrada foi a exclusão da mobilidade de capitais combinada a um sistema de taxas de câmbio fixas, porém ajustáveis, com a autonomia de políticas econômicas.

Com o aumento da mobilidade de capitais no início dos anos 1970 e a conseqüente derrocada do sistema de Bretton Woods tornou-se crescente a adoção de regimes cambiais intermediários por diversos países. A justificativa para este comportamento se deve ao fato de que tal estrutura não cria os desalinhamentos excessivos de um regime de câmbio flutuante e permite alguma independência para a realização de políticas econômicas. Esta foi a alternativa encontrada durante os anos 1980 e o início dos anos 1990 com a experiência do Sistema Monetário Europeu e por grande parte dos países emergentes.

Não obstante, a maioria dos países que adotaram a estrutura sobredita foi alvo de ataques especulativos que culminaram com a flexibilização ou mesmo o abandono desse tipo de regime de câmbio. No caso dos membros do Sistema Monetário Europeu foi observada uma ampliação das bandas cambiais de $\pm 2,25 \%$ para $\pm 15 \%$. Além disto, conforme apontado por Eichengreen (1994), um exemplo concreto de abandono do uso de regimes de câmbio intermediários é a formação de uma união monetária pelos países europeus e o aumento do uso do câmbio flutuante pelos países emergentes (Brasil, México, Argentina e alguns países asiáticos).

A partir do meado dos anos 1990 tornou-se fundamental para avaliar os regimes cambiais a necessidade de evitar o problema de inconsistência temporal na condução das políticas econômicas e a prevenção de crises. Sob esta perspectiva, a idéia de que escolhas bipolares (adoção de um regime de câmbio fixo ou flexível) seriam superiores à adoção de arranjos cambiais intermediários tornou-se dominante. ${ }^{1} \mathrm{~A}$ justificativa para esta visão é que os arranjos intermediários seriam difíceis de serem sustentados e mais propensos a crises.

Todavia, no final dos anos 1990, a visão supracitada passou a ser criticada por diversos autores. Frankel (1999), mostrando-se contrário à visão bipolar, defende o argumen-

1 A visão bipolar também é conhecida como "solução de canto" (corner solution) ou "desaparecimento do centro" (bollowing-out). 
to de que a obtenção de alguma estabilidade cambial concomitante à independência monetária seria factível devido à existência de graus variáveis de mobilidade de capitais entre as opções extremas de total controle de capitais e de perfeita mobilidade de capitais. Um outro agravante, conforme apontado por Lourenço (2004), é que os resultados empíricos favoráveis à solução bipolar mostraram-se frágeis devido às discrepâncias entre regimes cambiais oficiais, "de jure", e regimes cambiais efetivos, "de facto".

Além dos pontos acima, Levy-Yeyati e Sturzenegger (2002) e Fischer (2001) mostram argumentos contrários à aplicabilidade da visão bipolar ao caso de países em desenvolvimento. Os primeiros autores salientam que para a validade da "abordagem bipolar" seria necessária uma exposição a fortes fluxos de capitais, enquanto que Fischer (2001) salienta o fato de que os países que não se encontram nessa situação possuem um grande conjunto de opções de regimes cambiais intermediários. A idéia de que, no contexto das escolhas bipolares, os regimes de câmbios flexíveis seriam mais adequados para países de mercado emergente também é alvo de críticas. Segundo Calvo e Reinhart (2002), a preocupação dos bancos centrais com o impacto de variações na taxa de câmbio sobre a inflação e sobre os sistemas financeiros nacionais tem levado à intervenção deliberada na flutuação das moedas (utilização ativa de reservas e de taxa de juros) mesmo que os países tenham anunciado que adotam taxas de câmbio flexíveis. Este tipo de procedimento foi batizado por Reinhart (2000) como "medo de flutuar” (fear of floating). ${ }^{2}$

Independente da opção utilizada para o regime de câmbio, não é possível desprezar a mobilidade de capital em um mundo globalizado. A abordagem convencional do mercado de ativos implica que, em equilíbrio, o rendimento de dois ativos semelhantes mensurados na mesma moeda deve ser igual. Em outras palavras, a condição da paridade descoberta de juros determina que a taxa de juros doméstica $\left(i^{D}\right)$ equivale à taxa de juros estrangeira $\left(i^{*}\right)$ mais a desvalorização esperada da moeda nacional $\left[\left(E_{t+1}^{e}\right.\right.$ $\left.\left.-E_{t}\right) / E_{t}\right]$, isto é, $i^{D}=i^{*}+\left[\left(E_{t+1}^{e}-E_{t}\right) / E_{t}\right]$. A equação da paridade descoberta dos juros revela que tomando as expectativas como dadas a política monetária deve respeitar uma restrição que determina o nível de taxa de juros consistente com o equilíbrio externo. Destarte, conclui-se que independente do regime cambial em vigor a mobilidade de capitais tem o efeito de reduzir a autonomia das políticas econômicas domésticas. Este resultado foi classificado por Dornbusch (1998) como o primeiro corolário da mobilidade de capitais.

2 Em relação à adoção de uma união monetária, Eichengreen, Tobin e Wyplosz (1995) ressaltam que a flutuação cambial não é inevitável, pois as relações financeiras e comerciais com os países que não integram a união monetária não são eliminadas. Por outro lado, embora a flutuação cambial permita maior poder de discrição às autoridades monetárias, não deve ser desprezado o custo referente ao possível distanciamento da taxa de câmbio em relação à sua taxa de equilíbrio. 
Concomitante às transformações ocorridas quanto ao uso do regime de câmbio ao longo dos anos 1980 e 1990, a teoria referente à credibilidade da condução da política econômica apresentou avanços significativos nesse período. A antiga literatura sobre regras versus discrição, que se concentrava nas intenções e na capacidade do responsável pela política, foi alterada de forma substancial pelos estudos desenvolvidos por Kydland e Prescott (1977) e Barro e Gordon (1983). ${ }^{3}$ Antes desses estudos os principais argumentos para o uso de regras consistiam no conhecimento imperfeito sobre a economia e a tendência das autoridades políticas em conduzir a política econômica para fins inadequados do ponto de vista do bem-estar social. ${ }^{4}$ Esta perspectiva sobre regras ou discrição foi alterada de forma que as regras passaram a ser entendidas como um compromisso para a autoridade política.

A mudança na análise sobre regras versus discrição culminou com a necessidade de serem desenvolvidas estruturas para a política monetária que tivessem como preocupação básica a estabilidade de preços. Com essa finalidade, Rogoff (1985) elaborou o artigo que serve como referência básica para a literatura sobre a proposição de um banco central independente. A idéia central é que um banco central independente seria capaz de remover o viés inflacionário da condução da política monetária, pois deixaria de ceder às pressões do governo para o financiamento de déficits. ${ }^{5}$ Em geral, os modelos sobre credibilidade têm mostrado a importância de um anúncio crível para a condução da política econômica com o objetivo de reduzir a incerteza dos agentes econômicos e os sacrifícios das autoridades monetárias em atingir seus objetivos de longo prazo.

De forma análoga à proposição de independência do banco central, a idéia de liberalização da conta de capitais representa uma restrição à condução da política monetária. A necessidade de um comportamento transparente e responsável para a política se justifica pelo fato de o responsável por sua condução sofrer punição sob a forma de uma fuga de capitais (substituição de moedas). Os agentes reagem desta forma quando percebem uma perda no valor dos ativos que estão retendo devido a uma política monetária mais frouxa. No caso de relaxamento na administração da política monetária poderia haver dois resultados possíveis: (i) perda de reservas, no caso de um regime de câmbio intermediário; ou (ii) desvalorização cambial, no caso de um regime de câmbio flutuante. Assim, o aumento da elasticidade de substituição da moeda doméstica por moeda estrangeira, resultado da política de liberalização, tornaria a política monetária mais disciplinada e conservadora (avessa à inflação).

3 Para uma análise sobre a gênese e os desdobramentos da teoria da credibilidade ver Drazen (2000).

4 Um bom exemplo é o estudo elaborado por Friedman (1968).

5 Cukierman (1994) destaca o fato de que a experiência de países que convivem com elevada inflação tem demonstrado que a conquista da estabilidade tem sido obtida via desenvolvimento. Portanto, tal objetivo não pode ser alcançado somente pela delegação de autoridade para o BC. Além disso, a discussão sobre a independência do $\mathrm{BC}$ não depende apenas do aspecto econômico, mas também do político. Para uma análise sobre a teoria da independência do BC, ver Berger, de Haan e Eijffinger (2001). 
A idéia central contida no artigo é de que a liberalização da conta de capitais restringe o grau de autonomia da política monetária doméstica e contribui para a redução das taxas de inflação. Com base neste argumento é elaborada uma nova versão do modelo teórico de Gruben e McLeod (2001) e é feita uma análise empírica para o caso brasileiro com o objetivo de avaliar se o aumento da liberalização da conta de capitais no período posterior à introdução do Plano Real contribuiu para a estabilidade de preços. Além desta introdução, o artigo encontra-se dividido em mais três seções. A seção 1 faz uso de um modelo teórico para mostrar como uma menor restrição ao movimento de capitais pode contribuir para a obtenção de uma menor inflação; a seção 2 apresenta uma metodologia para a obtenção de um índice de controle de capitais e analisa as evidências empíricas entre o índice obtido e os índices de preços (IPCA e IGP-DI) por meio da aplicação de Vetores Auto-regressivos para o período posterior à introdução do Plano Real; por último, é apresentada a conclusão do artigo.

\section{O EFEITO DA LIBERALIZAÇÃO DA CONTA DE CAPITAIS SOBRE A IN- FLAÇÃO}

O modelo que será apresentado nesta seção segue, em grande medida, a linha sugerida por Agénor e Montiel (1996) e a análise de Gruben e McLeod (2001), exceto pela inclusão de uma restrição que será especificada a seguir. A finalidade desta seção é mostrar de que forma a liberalização da conta de capitais poderia contribuir para disciplinar o comportamento da autoridade em busca da estabilidade de preços. De acordo com a visão de Gruben e McLeod (2001) a liberalização da conta de capitais deve ser entendida como uma sinalização para os agentes econômicos de como a política monetária será conduzida no futuro. Em específico, é esperado que os agentes econômicos interpretem a liberalização da conta de capitais como um sinal do comprometimento do banco central na condução da política monetária para o combate à inflação. Este tipo de sinalização é importante, sobretudo para o caso de pequenas economias abertas, uma vez que na maioria dos casos a inflação elevada é resultado do financiamento do déficit público por meio de emissão monetária. ${ }^{6}$

A liberalização da conta de capitais seria capaz de disciplinar a condução da política monetária evitando que o banco central siga uma estratégia que coloque em risco a estabilidade de preços. Sob esta perspectiva, a autoridade monetária sinaliza ao público que está disposta a sofrer punições no caso de adotar uma política monetária inflacionária. Esta punição acontece por meio da substituição da moeda doméstica por moeda estrangeira (acarretando perda de reservas se o câmbio for fixo) ou aumento da inflação (se o câmbio for flutuante). Portanto, o banco central se depara com um

6 A principal justificativa para a rotina do uso de receitas de senhoriagem por essas economias se deve ao alto custo político da elevação da carga tributária. 
conflito entre a taxa de emissão monetária para garantir receitas ao governo e a defesa do poder de compra da moeda. Desta forma, o objetivo do banco central consiste em maximizar uma função utilidade dada por:

$$
U_{B C}=\theta_{l} S\left(\pi^{e}\right)+\theta_{2} \delta\left(\pi^{e}, \pi^{*}, \pi\right)
$$

onde, $\theta_{1}, \theta_{2}>0$;

o primeiro termo da equação indicado como s representa as receitas de senhoriagem; o segundo termo denotado por $\delta$ reflete os efeitos sobre a balança comercial e a conta de capitais (expressos em termos de variação de reservas ou do câmbio nominal). $\theta_{1}$ é o peso que o banco central atribui à receita de senhoriagem que é compensado pelo seu comprometimento com a preservação da taxa de câmbio $\theta_{2}$. Ademais, $\pi$ é a inflação esperada, $\pi^{*}$ representa a inflação externa, e $\pi$ corresponde à inflação observada. ${ }^{7}$

Dada a possibilidade de uso da receita de senhoriagem pelo governo para o financiamento do setor público, isto implica que o banco central deve levar em conta a dinâmica da dívida pública (equação 2) como uma restrição à sua função utilidade,

$$
\dot{b}=(g-t)+(r+\pi-x) b-s .^{8}
$$

Esta condição afirma que o endividamento do governo $(\dot{b})$ depende de três fatores: (i) do déficit primário $(g-t)$; (ii) da incidência da taxa de juros real $(r)$, da taxa de inflação observada, e da taxa de crescimento do PIB $(x)$ sobre o estoque da dívida pública; ${ }^{9}$ e (iii) da receita de senhoriagem.

Admitindo-se que a demanda por moeda é da forma semi-log de Cagan, isto implica que quando o mercado monetário está em equilíbrio obtém-se:

$$
s=\mu m_{0} \exp \left(-\alpha\left(\tau_{1}\right)\left(\pi^{e}-\pi^{*}\right)\right)
$$

onde,

7 Quanto maior o grau de independência da autoridade monetária menor é o valor de $\theta_{1}$.

8 Vale ressaltar que as variáveis na equação (2) encontram-se normalizadas pelo PIB. A inclusão desta equação representa um avanço em relação ao modelo de Gruben e McLeod (2001), uma vez que estes autores não tratam da questão fiscal, ou seja, o banco central não se preocupa com a trajetória da dívida pública.

9 Neste caso, a taxa de juros real e a taxa de inflação contribuem para a elevação do endividamento, enquanto que a taxa de crescimento do PIB contribui para a sua redução. 
$\mu$ é a taxa de crescimento da oferta de moeda $\left(m_{0}\right) ; \alpha$ é a elasticidade da demanda por moeda e depende, positivamente, do grau de liberalização da conta de capitais $\left(\tau_{1}\right) .^{10}$

Em relação ao imposto inflacionário é observado que o relaxamento do controle de capitais contribui para a redução de sua incidência sobre os agentes econômicos devido à facilitação em substituir a moeda doméstica por outra estrangeira. Sabendo-se que em equilíbrio as expectativas estão dadas, que a taxa de crescimento monetário equivale à taxa de inflação observada $(\mu=\pi)$, e que a taxa de crescimento monetário que maximiza a receita de senhoriagem corresponde a $\left(\alpha\left(\tau_{1}\right)\right)^{-1}$, isto implica que a liberalização da conta de capitais reduz a taxa de inflação que maximiza a receita de senhoriagem.

Os custos da senhoriagem são medidos em termos da perda potencial de reservas e/ou variações no câmbio nominal que ocorrem quando a inflação observada excede a inflação externa. Por sua vez, o volume de reservas disponível ao banco central e as variações no câmbio nominal dependem do saldo comercial e da entrada líquida de capitais. Em relação ao saldo comercial admite-se como sendo função do diferencial entre a inflação interna e a inflação externa e da liberalização relativa à conta corrente. A entrada líquida de capitais depende do diferencial entre a inflação esperada e a inflação externa e da liberalização do controle de capitais. Destarte, admitindo-se que a inflação externa é nula, a perda potencial de reservas e/ou variações no câmbio nominal são dadas por:

$$
\delta=\exp \left(\gamma_{1} \tau_{1} \pi^{e}+\gamma_{2} \tau_{2} \pi\right)
$$

onde,

$\gamma_{1} \tau_{1}$ é o efeito devido à inflação esperada $\left(\gamma_{1}\right)$ e à liberalização da conta de capitais $\left(\tau_{1}\right)$; e $\gamma_{2} \tau_{2}$ é o efeito devido ao impacto da inflação efetiva $\left(\gamma_{2}\right)$ e à liberalização da conta corrente $\left(\tau_{2}\right)$.

Assumindo-se que $m_{0}=1$ e mantendo-se a hipótese de que $\pi^{*}=0$, o problema da autoridade monetária consiste em maximizar a condição abaixo em relação à taxa de inflação:

$$
U_{B C}=\theta \mu \exp \left(-\alpha\left(\tau_{1}\right) \pi^{e}\right)-\exp \left(\gamma_{1} \tau_{1} \pi^{e}+\gamma_{2} \tau_{2} \pi\right)
$$

10 A demanda por moeda, tal como definida em (3), possibilita a incorporação do diferencial de juros na medida em que a paridade descoberta dos juros afirma que em um país com mobilidade plena de capitais, o retorno entre ativos internos e ativos internacionais devem ser iguais quando medidos em uma mesma moeda. Quando estes rendimentos são diferentes, supondo que os mercados são eficientes, este diferencial dá uma medida da presença de controle de capitais na economia, pois impede que operaçốes de arbitragem igualem os retornos. Assim, a paridade descoberta pode ser reescrita da forma: $\tau_{1}=i^{b}-i^{*}$ $\left[\left(E_{t+1}^{e}-E_{t}\right) / E_{t}\right]-v$, onde $v$ se refere à percepção de risco. Para mais detalhes, ver Williamson (2000). 
onde, $\theta=\theta_{1} / \theta_{2}$.

$$
\text { s.a. } \dot{b}=(g-t)+(r+\pi-x) b-\mu \exp \left(-\alpha\left(\tau_{1}\right) \pi^{e}\right)
$$

No caso de um regime discricionário as autoridades monetárias tomam as expectativas como dadas e, no equilíbrio, a inflação equivale à taxa de crescimento monetário $(\mu=\pi)$. Logo, fazendo-se uso do problema descrito em (5), e aplicando-se $\log$ em ambos os lados da igualdade obtêm-se a equação para a inflação doméstica resultante da maximização em relação à taxa de inflação,

$$
\pi=\ln \left[(\theta-\lambda) / \gamma_{2} \tau_{2}\right]\left(\alpha\left(\tau_{1}\right)+\gamma_{1} \tau_{1}+\gamma_{2} \tau_{2}\right)^{-1}
$$

onde $\lambda$ representa o multiplicador de Lagrange associado à variação da dívida.

A equação (6) apresenta implicações importantes para a análise da inflação interna. De acordo com a equação sobredita, uma ampliação na abertura da conta de capitais $\left(\tau_{l}\right)$ é capaz de reduzir a taxa de inflação que maximiza a função objetivo do banco central. A liberalização da conta de capitais tende a reduzir a taxa de emissão monetária, pois o banco central tem como objetivo não só a maximização da receita de senhoriagem, mas também a redução da possível perda de reservas ou desvalorização cambial geradas pela emissão monetária.

Uma observação importante é que $\lambda$ representa a sensibilidade da inflação a variações na dívida pública. Assim, em um ambiente de expansão do endividamento, a inflação se eleva devido à transmissão via $\lambda$. Outra possibilidade é que $\lambda$ pode se elevar quando a dívida estiver em um patamar elevado, mostrando que o BC está mais sensível à dívida do que ao comprometimento antiinflacionário. $\mathrm{O}$ segundo caso merece atenção, pois denota uma situação em que o $\mathrm{BC}$ estaria mais propenso a fazer uso do aumento da inflação para financiar a dívida pública.

$\mathrm{O}$ último ponto sobredito tem um significado importante, pois mostra que se o BC liberalizar a conta de capitais e reduzir a receita de senhoriagem para evitar uma possível fuga de capitais, há a necessidade de uma maior disciplina fiscal. Caso contrário, o estoque da dívida pública se expande devido à redução da receita de senhoriagem, fazendo com que, no futuro, ocorra a monetização da dívida, o que, por conseguinte, eleva a taxa de inflação e potencializa a fuga de capitais. Logo, a ausência de um equilíbrio fiscal faz com que a política em consideração careça de credibilidade.

No que se refere às evidências empíricas, observa-se que o estudo de cross country tem sido utilizado, na maioria das vezes, para avaliar a relação entre a liberalização da conta de capitais e a taxa de inflação. Ademais, os resultados encontrados na literatura não 
se mostram unívocos. Rodrik (1998) não encontrou evidências de que a liberalização da conta de capitais causou impacto significativo sobre a taxa de inflação no período 1975-1989. Por outro lado, Gruben e McLeod (2002) encontraram evidências de que a liberalização da conta de capitais ou da conta corrente contribuiu para uma redução de $3 \%$ a $6 \%$ na taxa de inflação anual média. ${ }^{11}$

\section{ANÁLISE EMPÍRICA PARA O CASO BRASILEIRO}

Com o objetivo de realizar a análise empírica foi construído um índice de controle de capitais (ICC) de janeiro de 1995 a dezembro de 2002. Para aferir o ICC foram levados em conta os decretos restritivos e os liberalizantes emitidos a cada mês. Estes decretos foram codificados em variáveis dummies com +1 para decretos restritivos (significando elevação nas restrições ao fluxo de capitais) e -1 para decretos liberalizantes (significando redução na restrição ao fluxo de capitais). Para cada mês foi realizado o saldo entre os decretos restritivos e liberalizantes. Assim, se em um mês o valor obtido foi negativo, o índice indica uma redução das restrições ao fluxo de capitais.

A metodologia supracitada levou em consideração apenas a legislação referente aos capitais de curto prazo (fluxos de portfólio). A justificativa teórica para esta escolha está no fato de que, de acordo com o modelo apresentado, a política monetária torna-se disciplinada em razão da possibilidade de fuga de capitais. Tal fuga de capitais tornase uma possibilidade real quando os fluxos de curto prazo tornam-se mais relevantes do que os investimentos diretos, uma vez que estes últimos não são influenciados por fatores macroeconômicos de curto prazo.

Em geral, este tipo de índice para avaliar a existência ou não de controles de capitais em uma economia tem sido alvo de duas críticas principais: (i) não leva em conta a importância relativa de cada decreto no aspecto qualitativo; e (ii) a emissão de um decreto restritivo não impede a ocorrência de transações no caso de haver presença de corrupção na administração pública. Embora a crítica apresentada no segundo ponto mostre-se razoável, no período recente Vieira e Holland (2003) e Cardoso e Goldfajn (1997) realizaram estudos empíricos com base em índices apoiados na legislação. Os resultados encontrados pelos autores mencionados sugerem que a utilização desses índices mostra-se relevante para a análise sobre a liberalização da conta de capitais.

A crítica contida no primeiro ponto não deve ser negligenciada, uma vez que o índice baseado na utilização de dummies pode conter erros de medida por não conseguir avaliar as diferenças qualitativas entre os decretos. Com o objetivo de eliminar o

11 Em relação à política fiscal, Kim (2003) encontrou evidências de que a liberalização da conta de capital é capaz de disciplinar o déficit público. 
problema apontado o ICC foi ajustado a partir de seus determinantes. De acordo com Cardoso e Goldfajn (1997), a necessidade da utilização de controle de capitais se deve aos seguintes motivos: (i) considerando-se o caso de regime de câmbio fixo, um influxo de capitais promoveria uma expansão da base monetária devido ao acúmulo de reservas que culminaria com um processo inflacionário; (ii) eliminar a tendência para a apreciação da taxa de câmbio real, uma vez que haveria prejuízo para o saldo da balança comercial (aumento das importações e redução das exportações); (iii) inibir o aumento da dívida pública resultante do uso de políticas de esterilização mantidas por meio de elevadas taxas de juros; e (iv) contribuiria para evitar fuga de capitais em momentos de crises financeiras.

Além dos pontos mencionados acima, Bartolini e Drazen (1997) afirmam que os países emergentes têm um grande incentivo em impor controle de capitais depois de terem adotado medidas liberalizantes no período anterior. A justificativa para este procedimento se deve ao fato de que associado à liberalização haveria um aumento no influxo de capitais para o país que adotou esta postura. Portanto, haveria motivos para o surgimento do problema de inconsistência temporal na política anunciada. Em virtude da forte entrada de capitais o governo ficaria tentado a impor controles sobre o fluxo no período seguinte, pois dessa forma evitaria a saída dos capitais que ingressaram no período anterior e aumentaria a receita governamental por meio da tributação incidente sobre os capitais que saíssem do país.

Levando em conta as observações acima, o ICC foi ajustado (ICCajust) a partir de seus determinantes. Para este ajuste foram considerados: a taxa de crescimento da base monetária; o saldo da conta corrente como proporção do PIB; a taxa de crescimento da dívida pública; dummy para o trimestre em que ocorreu a crise russa; os fluxos efetivos como proporção do PIB; a taxa de juros norte-americana (prime rate); e o ICC defasado em um período. ${ }^{12}$

A Figura 1 mostra a evolução do ICC ajustado para o período compreendido entre janeiro de 1995 e dezembro de 2002. Conforme pode ser observado, o ICC ajustado situou-se abaixo do valor zero durante a maior parte do tempo. Logo, observa-se que houve uma tendência liberalizante ao longo do período no Brasil..$^{13}$

12 Em estimaçôes prévias, uma dummy para a crise asiática foi testada e rejeitada. Além disto, várias especificações com defasagens alternativas foram testadas. Os resultados apresentados referem-se ao melhor ajuste obtido.

13 Agradecemos a um parecerista pela sugestão de ampliar o ICC ajustado para além do período em que vigorou uma variação do regime de câmbio fixo no Brasil. 


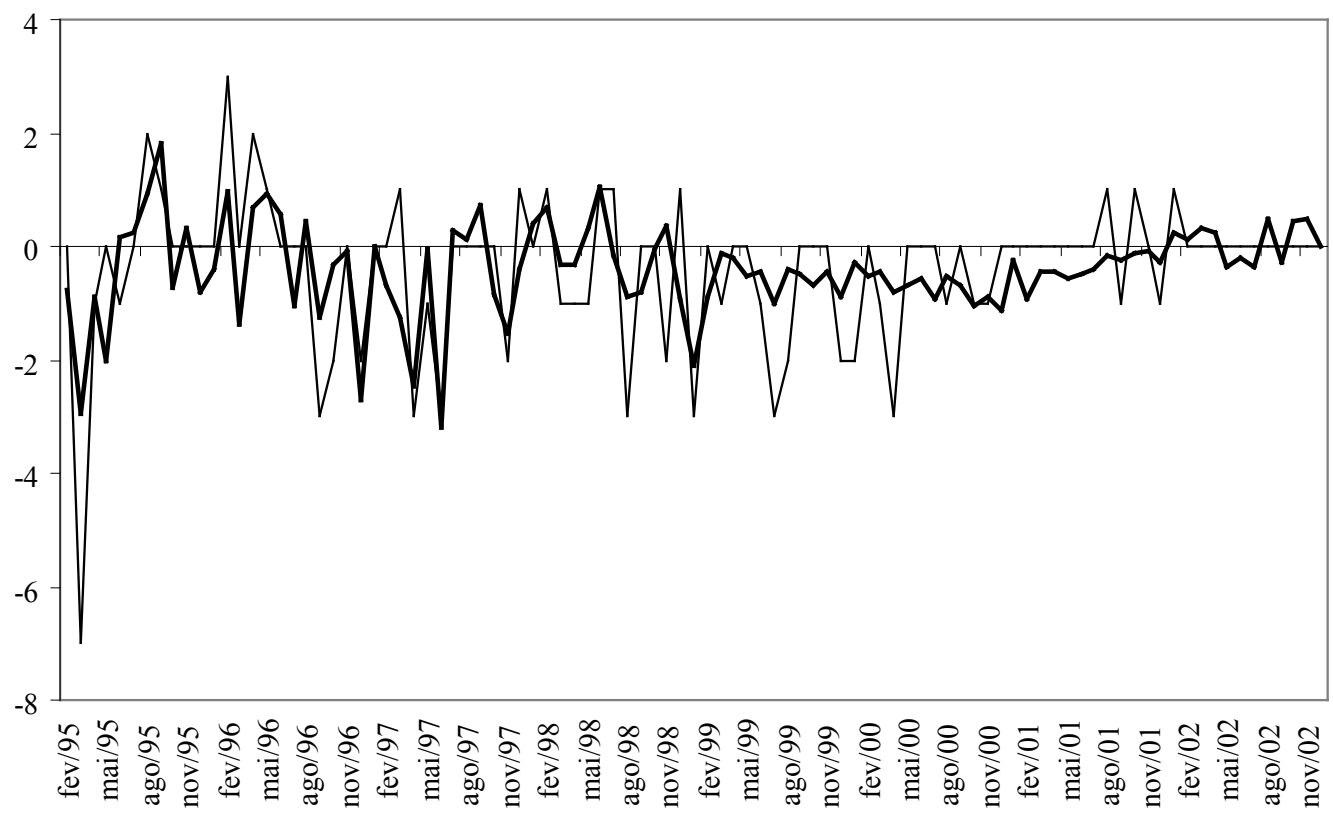

Com o intuito de avaliar a existência de uma quebra estrutural para o ICC devido à mudança do regime cambial ocorrida em janeiro de 1999, realizou-se o teste de estabilidade de parâmetros de Chow (Tabela 1). ${ }^{14}$ Para a realização do teste os dados foram divididos em dois subperíodos de forma que se for observada uma diferença significativa para as estimações relativas a cada subperíodo há uma mudança estrutural na relação sob análise. O primeiro intervalo de tempo se estende de fevereiro de 1995 a dezembro de 1998 - período de utilização de um regime de câmbio semifixo; enquanto que o segundo subperíodo compreende os meses de janeiro de 1999 a dezembro de 2002 - período em que o regime de câmbio tornou-se flutuante. $\mathrm{O}$ resultado obtido (vide Tabela 1) mostra que houve uma mudança estrutural. Logo, é indicado fazer a análise do período que se estende de fevereiro de 1995 a dezembro de 2002 por meio dos dois subperíodos mencionados. Uma outra justificativa para a escolha desses subperíodos se deve ao fato de que os efeitos esperados da liberalização da conta de capitais apresentam diferenças significativas em razão do regime de câmbio em vigor.

14 O teste de Chow compara a soma do quadrado dos resíduos obtida pela estimação da equação que abrange toda a amostra com a soma dos quadrados dos resíduos das equaçóes estimadas para cada subperíodo. 
TABELA 1 - TESTE DE CHOW - ESTABILIDADE DOS PARÂMETROS (1995:2 $-2002: 12)$

\begin{tabular}{lccc}
\hline \multicolumn{4}{c}{$\mathrm{ICC}=\mathrm{b}_{0}+\mathrm{b}_{1}$ jurosEUA $+\mathrm{b}_{2}$ Fluxo $+\mathrm{b}_{3} \mathrm{ICC}_{-1}+\mathrm{b}_{4}$ Dívida $+\mathrm{b}_{5} \mathrm{CC}+\mathrm{b}_{6} \mathrm{BM}$} \\
\hline Estatística $\mathrm{F}$ & 4,624387 & Probabilidade & 0,000216 \\
Razão de Verossimilhança & 31,94033 & Probabilidade & 0,000042 \\
\hline
\end{tabular}

Nota: Subperíodos 1995:2/1998:12, 1999:1/2002:12.

Para o cálculo do ICCajust foram feitas duas regressões (método mínimos quadrados - vide Tabelas 2 e 3). Em ambas as regressões a estatística F mostrou que as variáveis, em seu conjunto, são diferentes de zero. Contudo, deve-se notar que o ajuste para o período de câmbio flutuante possui uma qualidade significativamente inferior.

TABELA 2 - ICCAJUST 1995/1998 - DETERMINANTES (VARIÁVEL EXPLI$C A D A-I C C)$

\begin{tabular}{lcccc}
\hline Variável & Coeficiente & Desv. Padrão & Estatística-t & Probabilidade \\
\hline Constante & 0,410526 & 9,850573 & 0,041675 & 0,9670 \\
JurosEUA & $-0,030412$ & 1,898115 & $-0,016022$ & 0,9873 \\
Fluxo & 0,059843 & 0,068968 & 0,867696 & 0,3909 \\
ICC(-1) & $-0,189571$ & 0,119193 & $-1,590447$ & 0,1198 \\
Dívida & 0,816116 & 0,228346 & 3,574037 & 0,0010 \\
CC & 0,422158 & 0,128836 & 3,276710 & 0,0022 \\
Base Mon. & $-2,703659$ & 1,378255 & $-1,961654$ & 0,0570 \\
D Rússia & 0,904297 & 0,539181 & 1,677169 & 0,1015 \\
\hline & & Obs 47 & $\mathrm{R}^{2} 0,43$ & Estat-F 4,26 \\
\hline
\end{tabular}

Nota: Estatísticas-t consideram o teste de heteroscedasticidade de White (1980).

TABELA 3 - ICCAJUST 1999/2002 - DETERMINANTES (VARIÁVEL EXPLI$C A D A-I C C)$

\begin{tabular}{|c|c|c|c|c|}
\hline Variável & Coeficiente & Desv. Padrão & Estatística-t & Probabilidade \\
\hline Constante & 0,524875 & 0,258731 & 2,028648 & 0,0490 \\
\hline JurosEUA & $-0,187573$ & 0,077681 & $-2,414665$ & 0,0203 \\
\hline Fluxo & 0,044864 & 0,033788 & 1,327836 & 0,1916 \\
\hline $\operatorname{ICC}(-1)$ & $-0,000934$ & 0,179383 & $-0,005208$ & 0,9959 \\
\hline Dívida & $-0,050076$ & 0,030301 & $-1,652610$ & 0,1060 \\
\hline CC & 0,051360 & 0,069847 & 0,735317 & 0,4663 \\
\hline \multirow[t]{2}{*}{ Base Mon. } & $-1,577087$ & 0,069847 & $-0,855421$ & 0,3973 \\
\hline & & Obs 48 & $R^{2} 0,25$ & Estat-F 2,31 \\
\hline
\end{tabular}

Nota: Estatísticas-t consideram o teste de heteroscedasticidade de White (1980).

A justificativa para a diferença entre os ajustes nos dois períodos é explicada pelo fato de que em um regime de câmbio flutuante a presença de controles de capitais não é necessária para a manutenção do regime cambial. Por outro lado, em um regime de câmbio semifixo, controles de capitais podem contribuir para a manutenção do 
regime. Conforme atestado por Cardoso e Goldfajn (1997), os controles de capitais foram endógenos para o período em que havia a preocupação de regular a taxa de câmbio. Essa constatação é confirmada por meio da Figura 1, uma vez que os controles foram menos utilizados no período posterior à flexibilização da taxa de câmbio (principalmente a partir de 2001). Além disto, deve-se ressaltar que os dois subperíodos em consideração contemplam diferentes diretorias que estiveram à frente do Banco Central do Brasil (BCB). Logo, existe a possibilidade de haver funções de reação distintas do BCB para os dois subperíodos. ${ }^{15,16}$

\subsection{Resultados Empiricos}

Com o objetivo de verificar se o aprofundamento no processo de liberalização da conta de capitais contribuiu para o combate à inflação no período posterior à introdução do Plano Real é empregado um modelo de vetor auto-regressivo (VAR) na análise. Para tanto, foi mensurado o grau de liberalização da conta de capitais no Brasil por meio do índice apresentado na seção anterior (ICCajust). Além do ICCajust acumulado no período de janeiro de 1995 a dezembro de 2002 é utilizado no estudo os índices de preço (IPCA e IGP-DI) e a taxa de câmbio (R \$ US\$ - comercial - venda - média R\$ - mensal). ${ }^{17}$ A justificativa para a utilização de dois índices de preços na análise advém do fato de que a principal diferença entre o IGP-DI e o IPCA é que o primeiro considera preços no atacado, com ponderação duas vezes superior à dos preços ao consumidor, e custos da construção civil, além dos preços ao consumidor. Neste estudo o ponto importante de distinção entre esses índices refere-se à maior sensibilidade do IGP-DI às alterações na taxa de câmbio, em razão dos repasses mais rápidos e completos aos preços internos no atacado. Destarte, depreciações na taxa de câmbio provocam um aumento no nível geral de preços acima do nível de preços ao consumidor.

Uma primeira condição a ser avaliada para a implementação de um modelo VAR consiste em verificar se as séries ICCajust, IPCA, IGP-DI e câmbio possuem raiz

15 O exemplo típico para esta observação é o impacto da taxa de juros norte-americana sobre o ICC. No primeiro período ela não possui significância estatística, porém no segundo período, dentre as variáveis, ela é a mais significativa, o que denota diferentes respostas para diferentes períodos.

16 Apesar de o ajuste obtido na segunda regressão estimada não ter sido muito elevado, optou-se por utilizar o ICC ajustado devido ao interesse em se analisar os impactos macroeconômicos dos controles de capitais. A menor robustez estatística não significa uma fraqueza da metodologia; a justificativa para o resultado encontrado se deve ao fato de que os impactos macroeconômicos foram mais limitados neste subperíodo ou que os erros de medida foram mais importantes do que era esperado entre os subperíodos.

17 A justificativa para a utilização dos dois índices para a mensuração da inflação se deve ao fato de haver dissensões significativas entre esses índices quando se considera o impacto proveniente da taxa de câmbio. 
unitária para os subperíodos 1995-1998 e 1999-2002. ${ }^{18}$ Com o objetivo de testar a existência ou não de raiz unitária das séries supracitadas foi realizado o teste ampliado de Dickey-Fuller (ADF) e o teste Phillip-Perron (PP). O procedimento básico para a realização dos testes desenvolvidos por Dickey e Fuller (1979, 1981) consiste em regredir a primeira diferença de uma série $\left(H_{t}\right)$ contra seus valores defasados em um período $\left(H_{t-1}\right)$. Em seguida, é testada a significância estatística do parâmetro associado a $H_{t-1}$. Dado que na maioria das vezes os resíduos são autocorrelacionados, o teste ampliado de Dickey-Fuller incorpora à equação especificada as primeiras diferenças defasadas $(p)$ de $\Delta H_{t}$ de forma que os resíduos tornem-se um ruído branco (média zero, variância constante, e ausência de autocorrelação serial). Logo, a equação que possui constante e tendência tem a seguinte especificação:

$$
\Delta H_{t}=\beta+\delta T+\gamma H_{t-1}+\eta_{1} \Delta H_{t-1}+\eta_{2} \Delta H_{t-2}+\ldots+\eta_{p-1} \Delta H_{t-p+1}+s_{t}
$$

Uma aplicação satisfatória do teste de raiz unitária de Dickey e Fuller implica a necessidade de que a série testada não possua problema de autocorrelação serial, heteroscedasticidade, mudança estrutural ou sazonalidade. Com o objetivo de considerar os problemas de heteroscedasticidade e dependência serial, Phillips e Perron (1988) elaboraram um teste de raiz unitária que realiza ajustes não paramétricos nas estatísticas obtidas com o teste DF. Nesse sentido, a estatística do teste, $P P(t)$, para a estimativa do parâmetro $\rho$ nas especificações:

$$
\Delta H_{t}=\gamma H_{t-1}+u_{t} ; \quad \Delta H_{t}=\alpha+\gamma H_{t-1}+v_{t} ; \quad \Delta H_{t}=\beta+\delta T+\gamma H_{t-1}+s_{t} ;
$$

sendo $\Delta H_{t}=H_{t}-H_{t-1} \quad e \quad \gamma=\rho-1$, é definida como:

$$
P P(t)=\frac{\gamma_{0}^{1 / 2} t_{\rho}}{\lambda}-\frac{\left(\lambda^{2}-\gamma_{0}\right) n s_{\rho}}{2 \lambda S}
$$

onde,

$$
\lambda^{2}=\gamma_{0}+2 \sum_{j=1}^{q}\left(1-\frac{j}{q+1}\right) \gamma_{j}, \gamma_{j}=n^{-1} \sum_{t=j+1}^{n} \hat{u}_{t} \hat{u}_{t-j} ., S=\left(\frac{n}{n-k-1} \gamma_{0}\right)^{1 / 2}
$$

18 Em um modelo VAR o valor corrente de uma variável $y_{t}$ é explicado por seus próprios valores defasados e por valores defasados da variável $\mathrm{x}$, adicionados a um termo estocástico $e_{t}$. De forma análoga, o valor de $x_{t}$ é explicado por seus valores defasados, pelos valores defasados de $y_{t}$ e por um termo $\mu_{t}$. E admitido que o termo estocástico tem média zero, variância constante $\sigma_{\mu}^{2}$ e que não apresenta correlação serial. Portanto, será considerado na análise apenas regularidades e padrões passados de dados históricos como base para previsão. 
$t_{\rho} e s_{\rho}$ são, respectivamente, a estatística $t$ e o erro padrão do $\rho$ estimado associado a $H_{t-1} S$ é o erro padrão da estimativa da equação do teste, $q$ o número de defasagens, $k$ o número de variáveis incluídas na equação do teste, e $n$ o tamanho da amostra. ${ }^{19}$

Devido ao baixo poder dos testes ADF e PP em rejeitar a hipótese nula de raiz unitária e aos problemas de distorção do valor do teste quando a distribuição dos resíduos contém componentes de média móvel, ${ }^{20}$ Kwiatkowski, Phillips, Schmidt e Shin (1992) - KPSS - desenvolveram um teste para testar a estacionariedade da série. O teste KPSS é um teste multiplicador de Lagrange (LM) de constância do parâmetro $\zeta_{\mathrm{t}}$ no modelo:

$$
y_{t}=\delta t+\zeta_{t}+\varepsilon_{t}
$$

onde $\varepsilon_{t}$ é estacionário e $\zeta_{t}$ é um passeio aleatório, dado por $\zeta_{t}=\zeta_{t-1}+u_{t} u_{t} \sim i i d\left(0, \sigma_{u}^{2}\right)$. A hipótese nula é $H_{0}: \sigma_{u}^{2}=0$ e a estatística é dada pelo multiplicador de Lagrange:

$$
L M=\sum_{t=1}^{T} S_{t}^{2} / \hat{\sigma}_{L P e}^{2}
$$

onde o denominador é uma estimativa da variância de longo prazo dos resíduos estimados de $y_{t} ; S_{t}=\sum_{s=1}^{T} \hat{\varepsilon}_{s}$ e $\widehat{\varepsilon}_{s}$ são os resíduos estimados de $\varepsilon_{s}$. O modelo com $\delta t=0$ é utilizado para o teste de estacionariedade em torno do nível.

O teste KPSS tem sido apontado na literatura como confirmatório dos testes que têm a hipótese de raízes unitárias como nula. Dado que as hipóteses nulas são opostas, a ocorrência de resultados opostos, ou seja, a rejeição da hipótese nula em um teste e não rejeição no outro confirmariam as conclusões acerca da presença de raízes unitárias em determinada série.

A Tabela 4 apresenta um resumo do resultado dos testes ADF, PP e KPSS para as séries em consideração. ${ }^{21}$ Como os testes ADF e PP apresentam evidências distintas do KPSS, para as séries câmbio (nos dois períodos), IGP-DI e IPCA (1995-1998), é necessário utilizar outros critérios de decisão mais subjetivos. Para tanto, é feita uma análise dos correlogramas das séries, onde a queda lenta do coeficiente de autocorrelação amostral evidencia a existência de raiz unitária e a queda rápida evidencia a estacionariedade. Por meio de inspeção gráfica dos correlogramas dos valores originais

19 Os valores críticos para a estatística são os mesmos dos testes de Dickey-Fuller.

20 Ver Enders (1995) e Maddala e Kim (1998).

21 O apêndice A.l apresenta os testes de raiz unitária e estacionariedade para as séries. 
das séries supracitadas (vide Figura A.2.1, no apêndice) verifica-se que as séries câmbio (para ambos os períodos) e IGP-DI (1995-1998) são I(1), enquanto que a série IPCA é I(2) para o período 1995-1998.

\section{TABELA 4 - RESUMO DOS TESTES DE RAIZ UNITÁRIA E ESTACIO- NARIEDADE}

\begin{tabular}{lccc}
\hline$(1999-2002)$ & ADF & PP & KPSS \\
\hline Câmbio & $\mathrm{I}(1)$ & $\mathrm{I}(1)$ & $\mathrm{I}(0)$ \\
ICCajust & $\mathrm{I}(0)$ & $\mathrm{I}(0)$ & $\mathrm{I}(0)$ \\
IGP-DI & $\mathrm{I}(0)$ & $\mathrm{I}(0)$ & $\mathrm{I}(0)$ \\
IPCA & $\mathrm{I}(0)$ & $\mathrm{I}(0)$ & $\mathrm{I}(0)$ \\
\hline$(1995-1998)$ & & & $\mathrm{I}(0)$ \\
Câmbio & $\mathrm{I}(1)$ & $\mathrm{I}(1)$ & $\mathrm{I}(0)$ \\
ICCajust & $\mathrm{I}(0)$ & $\mathrm{I}(0)$ & $\mathrm{I}(1)$ \\
IGP-DI & $\mathrm{I}(2)$ & $\mathrm{I}(1)$ \\
IPCA & $\mathrm{I}(2)$ & $\mathrm{I}(2)$ & \\
\hline
\end{tabular}

Com o objetivo de analisar a relação entre os índices de preço, o câmbio e o controle de capitais para antes e depois da mudança do regime cambial ocorrida em janeiro de 1999 são elaborados dois VAR para cada período. O primeiro (modelo l) é formado pelo conjunto de variáveis câmbio, ICCajust e IGP-DI, enquanto que o segundo (modelo 2) é constituído por câmbio, ICCajust e IPCA. Em relação à definição do modelo aplicado para a elaboração dos VAR foram utilizados os critérios de Akaike (AIC), Schwarz (SIC) e Hannan-Quinn (HQ). ${ }^{22}$ Conforme pode ser observado pelos resultados presentes nas Tabelas A.7 e A.8 (vide apêndice) é adequada a utilização de três defasagens e o uso de constante para o modelo 1 (ambos os períodos). Para o modelo 2 também é aplicada constante para ambos os períodos, sendo que para o primeiro é aplicada uma defasagem enquanto que para o segundo são utilizadas duas defasagens. A curta defasagem dos VAR é consistente com o fato de se estar utilizando séries de freqüência mensal.

Assumindo-se que os erros são ortogonalizados pela decomposição de Cholesky para a estimação do VAR, isto implica que o ordenamento das variáveis é de crucial importância para a análise da função impulso-resposta e da decomposição da variância.

$22 A I C=-2(l / T)+2(k / T), S C=-2(l / T)+k \log (T) / T$ e $H Q=-2(l / T)+2 k \log (\log (T)) / T$; considera uma regressão com $\mathrm{k}$ parâmetros estimados usando T observaçốes. $l$ é o valor do $\log$ da função probabilidade com $k$ parâmetros estimados. 
Conforme pode ser observado pelo teste de precedência temporal de Granger (1969) ${ }^{23}$ (vide Tabelas A.9 e A.10 - apêndice), a ordenação que se mostra razoável para análise de ambos os modelos é dada por: ICCajust, câmbio e o índice de preço correspondente. Esse resultado é consistente com a análise que se pretende realizar, uma vez que é esperado que o uso (ausência) de controles de capitais tenha algum efeito sobre o nível geral de preços na economia. Ademais, o fato de a taxa de câmbio preceder os índices de preços mostra-se compatível com a idéia de que a mesma é um importante mecanismo de transmissão para a flutuação dos preços.

\subsubsection{Período 1995-1998}

Devido ao fato dos dados utilizados na amostra serem mensais, a Tabela 5 mostra a explicação da variância das variáveis que compõem os modelos 1 e 2 para os primeiros 12 meses. O mesmo período é assumido quando é feita a análise impulso-resposta para o VAR. De acordo com a Tabela 5 , verifica-se que a explicação da variância da liberalização da conta de capitais por meio dos índices de preços e da taxa de câmbio é inexpressiva para ambos os modelos. Em relação à variância da variável câmbio, verifica-se que a importância relativa da liberalização da conta de capitais tem papel diferenciado nos dois modelos. No modelo 1 a importância relativa do ICC ajustado é de aproximadamente $8 \%$, enquanto que no modelo 2 a relevância cai para quase a metade do caso anterior. Por outro lado, a importância relativa dos índices de preços na explicação da variância do câmbio tem papel semelhante nos dois modelos.

A grande diferença entre os modelos consiste na análise da variância para os índices de preços. No modelo 1 o ICC ajustado na explicação da variância do IGP-DI tem início com $10 \%$, mas decresce em seguida e estaciona para um nível próximo a 7\%. No modelo 2 ocorre o inverso, o ICC ajustado tem uma importância relativa inicial de cerca de $6 \%$ e se estabiliza a partir do segundo mês para aproximadamente $11 \%$. Esse resultado sugere que a magnitude da importância do ICC para a variância dos índices de preços depende, em alguma medida, da sensibilidade do índice de preços ao câmbio. No caso em consideração, observa-se que a menor sensibilidade do índice de preços à taxa de câmbio faz com que o ICC ajustado tenha um papel mais proeminente na explicação da variância do IPCA. Também deve ser ressaltada a diferença observada para a relevância da taxa de câmbio na análise da decomposição da inflação nos dois modelos. Enquanto no modelo que considera o IPCA a importância relativa da taxa de câmbio é limitada a 4\%, no modelo que considera o IGP-DI sua importância supera os $16 \%$.

23 O teste de Granger avalia se uma série de tempo $X_{t}$ "causa" outra série $\Upsilon_{t}$, se esta for prevista de forma mais adequada pelos valores passados de $X_{t}$, e por outras variáveis relevantes, inclusive valores passados do próprio $\Upsilon_{t}$. 


\section{TABELA 5 - DECOMPOSIÇÃO DA VARIÂNCIA}

\begin{tabular}{|c|c|c|c|c|c|c|c|c|c|}
\hline \multicolumn{10}{|c|}{ Modelo 1} \\
\hline Mês & \multicolumn{3}{|c|}{ ICCajust } & \multicolumn{3}{|c|}{ Dcambio } & \multicolumn{3}{|c|}{ DIGP-DI } \\
\hline & ICCajust & Dcambio & DIGP-DI & ICCajust & Dcambio & DIGP-DI & ICCajust & Dcambio & DIGP-DI \\
\hline 1 & 100,0000 & 0,000000 & 0,000000 & 2,699322 & 97,30068 & 0,000000 & 10,38599 & 4,768237 & 84,84577 \\
\hline 2 & 97,94302 & 1,506590 & 0,550395 & 3,442047 & 93,22036 & 3,337593 & 5,849995 & 13,30264 & 80,84737 \\
\hline 3 & 96,85093 & 1,537223 & 1,611852 & 4,291132 & 91,02380 & 4,685063 & 6,469850 & 14,27462 & 79,25553 \\
\hline 4 & 96,39748 & 1,605663 & 1,996861 & 7,460311 & 85,05044 & 7,489251 & 6,882274 & 15,15917 & 77,95856 \\
\hline 5 & 96,33699 & 1,667592 & 1,995419 & 7,438496 & 85,09282 & 7,468686 & 6,727401 & 16,23641 & 77,03619 \\
\hline 6 & 96,09393 & 1,818630 & 2,087437 & 7,435322 & 84,48271 & 8,081972 & 6,742989 & 16,23667 & 77,02034 \\
\hline 7 & 95,96636 & 1,911465 & 2,122177 & 7,500158 & 84,40479 & 8,095052 & 6,740191 & 16,24282 & 77,01699 \\
\hline 8 & 95,96493 & 1,912830 & 2,122244 & 7,500590 & 84,39798 & 8,101432 & 6,772777 & 16,22094 & 77,00628 \\
\hline 9 & 95,95402 & 1,915309 & 2,130674 & 7,493371 & 84,39412 & 8,112509 & 6,780336 & 16,22029 & 76,99937 \\
\hline 10 & 95,95278 & 1,915264 & 2,131951 & 7,507660 & 84,37103 & 8,121309 & 6,775310 & 16,24033 & 76,98436 \\
\hline 11 & 95,94949 & 1,916726 & 2,133788 & 7,508691 & 84,36877 & 8,122536 & 6,773861 & 16,24896 & 76,97718 \\
\hline 12 & 95,94634 & 1,917489 & 2,136171 & 7,510102 & 84,35715 & 8,132747 & 6,773530 & 16,24986 & 76,97661 \\
\hline \multicolumn{10}{|c|}{ Modelo 2} \\
\hline Mês & \multicolumn{3}{|c|}{ ICCajust } & \multicolumn{3}{|c|}{ Dcambio } & \multicolumn{3}{|c|}{ DIPCA,2 } \\
\hline & ICCajust & Dcambio & DIPCA,2 & ICCajust & Dcambio & DIPCA,2 & ICCajust & Dcambio & DIPCA,2 \\
\hline 1 & 100,0000 & 0,000000 & 0,000000 & 2,452497 & 97,54750 & 0,000000 & 6,208849 & 0,000161 & 93,79099 \\
\hline 2 & 99,36746 & 0,044462 & 0,588079 & 3,229760 & 90,00341 & 6,766830 & 10,61306 & 3,383252 & 86,00368 \\
\hline 3 & 99,31896 & 0,066935 & 0,614104 & 3,618263 & 89,20546 & 7,176272 & 10,58279 & 3,783925 & 85,63328 \\
\hline 4 & 99,31575 & 0,069746 & 0,614506 & 3,623383 & 89,20285 & 7,173767 & 10,59336 & 3,781290 & 85,62535 \\
\hline 5 & 99,31538 & 0,069748 & 0,614869 & 3,624233 & 89,19788 & 7,177887 & 10,59510 & 3,783614 & 85,62128 \\
\hline 6 & 99,31536 & 0,069765 & 0,614880 & 3,624454 & 89,19748 & 7,178066 & 10,59507 & 3,783814 & 85,62111 \\
\hline 7 & 99,31535 & 0,069766 & 0,614881 & 3,624455 & 89,19748 & 7,178067 & 10,59508 & 3,783812 & 85,62111 \\
\hline 8 & 99,31535 & 0,069766 & 0,614881 & 3,624456 & 89,19747 & 7,178070 & 10,59508 & 3,783814 & 85,62110 \\
\hline 9 & 99,31535 & 0,069766 & 0,614881 & 3,624456 & 89,19747 & 7,178070 & 10,59508 & 3,783814 & 85,62110 \\
\hline 10 & 99,31535 & 0,069766 & 0,614881 & 3,624456 & 89,19747 & 7,178070 & 10,59508 & 3,783814 & 85,62110 \\
\hline 11 & 99,31535 & 0,069766 & 0,614881 & 3,624456 & 89,19747 & 7,178070 & 10,59508 & 3,783814 & 85,62110 \\
\hline 12 & 99,31535 & 0,069766 & 0,614881 & 3,624456 & 89,19747 & 7,178070 & 10,59508 & 3,783814 & 85,62110 \\
\hline
\end{tabular}

A Figura 2, referente ao modelo 1, mostra que os efeitos de choques externos, transmitidos pelas variáveis em consideração para o ICC ajustado e a taxa de câmbio, não apresentam significância estatística. Além do esperado efeito de curto prazo da taxa de câmbio sobre o IGP-DI (vide segundo gráfico localizado na última linha), observa-se que os impactos decorrentes de choques externos transmitidos pela variável IGP-DI para si mesma tendem a decrescer à medida que o tempo passa (vide terceiro gráfico da linha supradita). Da mesma forma como foi detectado pela análise da decomposição da variância, observa-se que os efeitos de choques externos, transmitidos pela variável ICCajust sobre o IGP-DI (gráfico localizado no canto inferior esquerdo), indicam uma queda gradual à medida que o tempo avança. Em outras palavras, um aumento no ICCajust (aumento da restrição ao movimento de capitais) está associado a uma redução da taxa de inflação que é eliminada a partir do quinto mês. 
FIGURA 2 - FUNÇÕES DE RESPOSTA A IMPULSO PARA O VAR - MODELO I
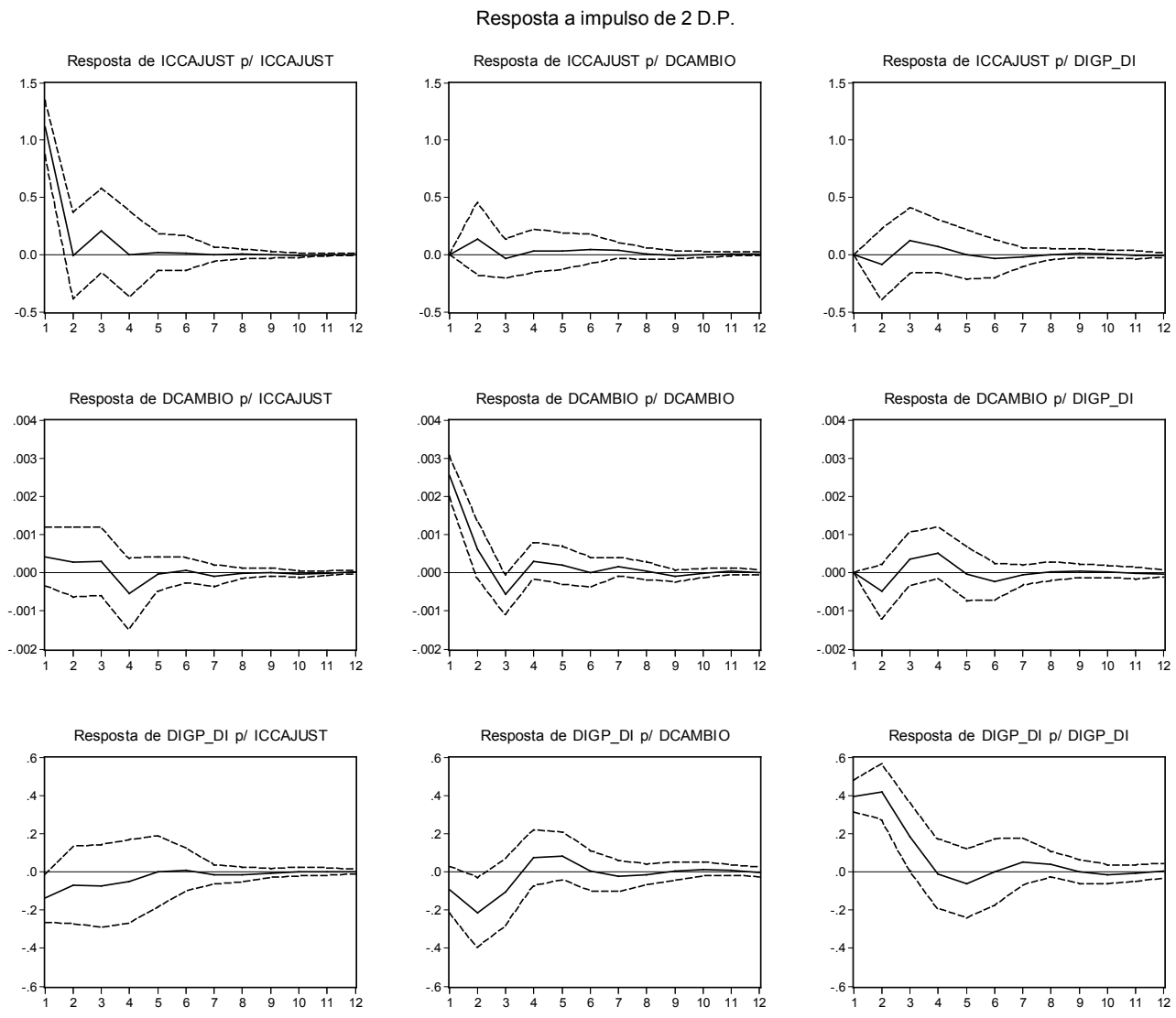

A análise das funções de impulsos-respostas para o modelo 2 (vide Figura 3) é bastante similar à do modelo anterior. A principal diferença refere-se à menor duração da resposta do IPCA aos choques transmitidos pelo ICC ajustado (gráfico localizado no canto inferior esquerdo). 
FIGURA 3 - FUNCOOEES DE RESPOSTA A IMPULSO PARA O VAR - MODELO 2

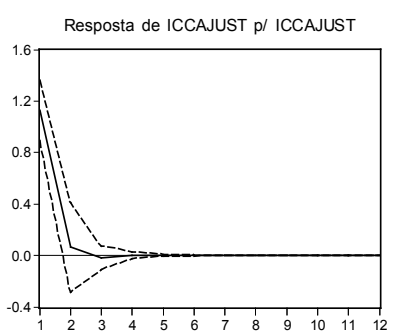

Resposta a impulso de 2 D.P.
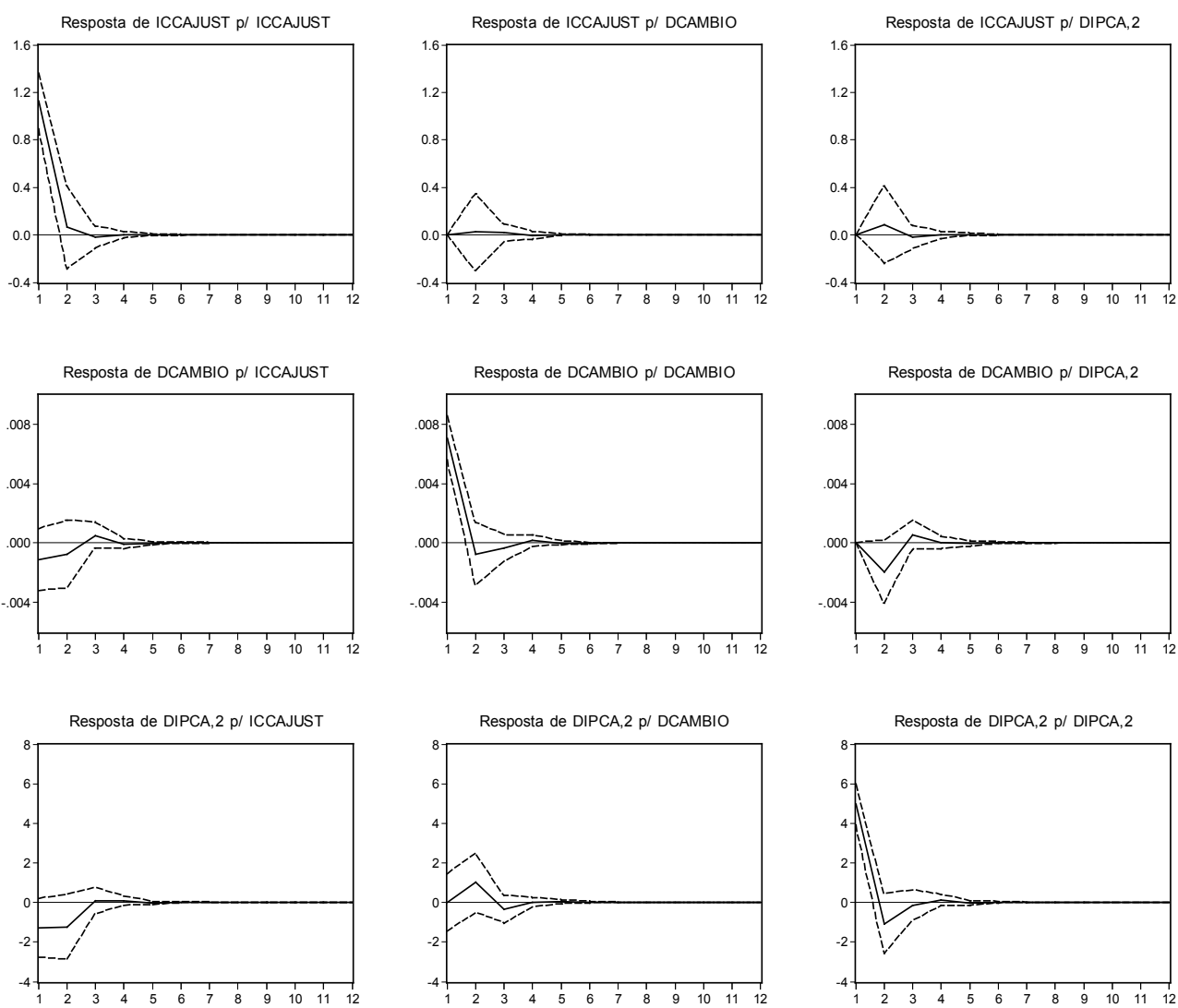

\subsubsection{Período 1999-2002}

A análise da decomposição da variância (vide Tabela 6) mostra um comportamento distinto daquele observado para o período anterior. No modelo 1 é observado que o câmbio passa a ser a variável-chave na explicação da variância das demais variáveis. Destaque para a importância relativa do câmbio para a variância do IGP-DI (86\%). Da mesma forma que no período anterior, a importância do ICC ajustado na explicação da variância do IGP-DI iniciou-se próxima a 10\%. Entretanto, ela decresce rapidamente a partir do terceiro mês e torna-se inexpressiva. Também é importante ressaltar que embora o ICC ajustado não se mostre relevante na explicação da variância do IGP-DI é observado que o mesmo é relevante para a análise da variância da taxa de câmbio (33\%). 
TABELA 6 - DECOMPOSIÇÃO DA VARIÂNCIA

\begin{tabular}{|c|c|c|c|c|c|c|c|c|c|}
\hline \multicolumn{10}{|c|}{ Modelo 1} \\
\hline Mês & \multicolumn{3}{|c|}{ ICCajust } & \multicolumn{3}{|c|}{ Dcambio } & \multicolumn{3}{|c|}{ IGP-DI } \\
\hline & ICCajust & Dcambio & IGP-DI & ICCajust & Dcambio & IGP-DI & ICCajust & Dcambio & IGP-DI \\
\hline 1 & 100,0000 & 0,000000 & 0,000000 & 9,861270 & 90,13873 & 0,000000 & 9,780859 & 35,25120 & 54,96794 \\
\hline 2 & 90,64197 & 8,432032 & 0,925996 & 31,53865 & 67,74449 & 0,716862 & 10,44153 & 46,07015 & 43,48831 \\
\hline 3 & 90,43472 & 8,552426 & 1,012858 & 32,09686 & 67,17004 & 0,733095 & 6,914772 & 53,95105 & 39,13418 \\
\hline 4 & 88,33255 & 9,083948 & 2,583507 & 34,91010 & 64,41746 & 0,672443 & 4,132142 & 63,42262 & 32,44524 \\
\hline 5 & 80,12966 & 14,62828 & 5,242060 & 34,46652 & 64,76222 & 0,771253 & 2,798610 & 71,73132 & 25,47007 \\
\hline 6 & 75,50000 & 17,99034 & 6,509658 & 34,40732 & 64,82332 & 0,769364 & 2,246180 & 77,33646 & 20,41736 \\
\hline 7 & 72,13920 & 21,33679 & 6,524001 & 34,18347 & 64,79217 & 1,024361 & 1,985813 & 80,82664 & 17,18755 \\
\hline 8 & 68,55066 & 25,24988 & 6,199456 & 33,73557 & 64,99560 & 1,268830 & 1,803696 & 82,94582 & 15,25048 \\
\hline 9 & 66,90228 & 27,00672 & 6,091005 & 33,56271 & 65,02304 & 1,414251 & 1,610005 & 84,14098 & 14,24902 \\
\hline 10 & 66,02328 & 27,95914 & 6,017584 & 33,32509 & 65,21876 & 1,456154 & 1,395011 & 84,82470 & 13,78029 \\
\hline 11 & 64,64169 & 29,17615 & 6,182159 & 33,00022 & 65,55779 & 1,441987 & 1,196993 & 85,36954 & 13,43347 \\
\hline 12 & 62,75204 & 30,61880 & 6,629160 & 32,89835 & 65,66160 & 1,440046 & 1,041204 & 85,95597 & 13,00282 \\
\hline \multicolumn{10}{|c|}{ Modelo 2} \\
\hline Mês & \multicolumn{3}{|c|}{ ICCajust } & \multicolumn{3}{|c|}{ Dcambio } & \multicolumn{3}{|c|}{ DIPCA,2 } \\
\hline & ICCajust & Dcambio & IPCA & ICCajust & Dcambio & IPCA & ICCajust & Dcambio & IPCA \\
\hline 1 & 100,0000 & 0,000000 & 0,000000 & 9,287179 & 90,71282 & 0,000000 & 0,923060 & 11,60452 & 87,47242 \\
\hline 2 & 92,81412 & 1,713867 & 5,472013 & 31,06496 & 68,78465 & 0,150388 & 1,374941 & 4,140627 & 94,48443 \\
\hline 3 & 89,66663 & 1,891947 & 8,441420 & 32,22426 & 66,15628 & 1,619451 & 2,597151 & 5,520326 & 91,88252 \\
\hline 4 & 88,26916 & 2,596801 & 9,134037 & 34,57198 & 63,82423 & 1,603794 & 3,537674 & 9,983276 & 86,47905 \\
\hline 5 & 86,49507 & 3,806688 & 9,698238 & 34,49815 & 63,73721 & 1,764642 & 3,385851 & 13,99217 & 82,62198 \\
\hline 6 & 85,30345 & 4,397936 & 10,29862 & 34,46080 & 63,70287 & 1,836322 & 2,922985 & 16,97544 & 80,10157 \\
\hline 7 & 84,44269 & 4,723474 & 10,83384 & 34,44604 & 63,67917 & 1,874791 & 2,518099 & 19,01576 & 78,46614 \\
\hline 8 & 83,55074 & 5,021265 & 11,42799 & 34,43209 & 63,65446 & 1,913449 & 2,200766 & 20,44441 & 77,35482 \\
\hline 9 & 82,62324 & 5,287819 & 12,08895 & 34,42060 & 63,63895 & 1,940447 & 1,954795 & 21,52596 & 76,51924 \\
\hline 10 & 81,69325 & 5,543885 & 12,76286 & 34,40609 & 63,62782 & 1,966090 & 1,765578 & 22,38632 & 75,84810 \\
\hline 11 & 80,72931 & 5,815680 & 13,45501 & 34,38937 & 63,61171 & 1,998919 & 1,616425 & 23,08623 & 75,29735 \\
\hline 12 & 79,72466 & 6,097620 & 14,17772 & 34,37177 & 63,59191 & 2,036328 & 1,495005 & 23,66284 & 74,84216 \\
\hline
\end{tabular}

O modelo 2 apresenta resultados distintos do anterior no que se refere à importância da taxa de câmbio para a explicação da variância das outras variáveis. A variância do índice de preços é explicada, em grande medida, pela própria variável (75\%). Portanto, de forma diferente do modelo 1 , a taxa de câmbio, apesar de relevante na explicação da variância (24\%), desempenha papel secundário neste caso. Ademais, o ICC ajustado não se mostra significante para a explicação da variância do IPCA. O ponto comum entre os dois modelos é a influência expressiva do ICC ajustado sobre a variância da taxa de câmbio (34\%). 
FIGURA 4 - FUNÇÕES DE RESPOSTA A IMPULSO PARA O VAR - MODELO I

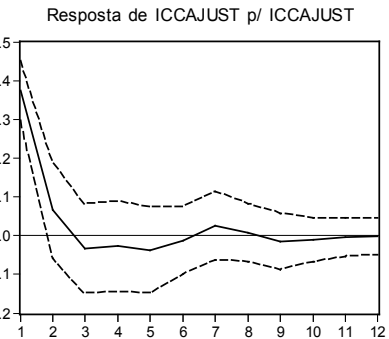

Resposta a impulso de 2 D.P.
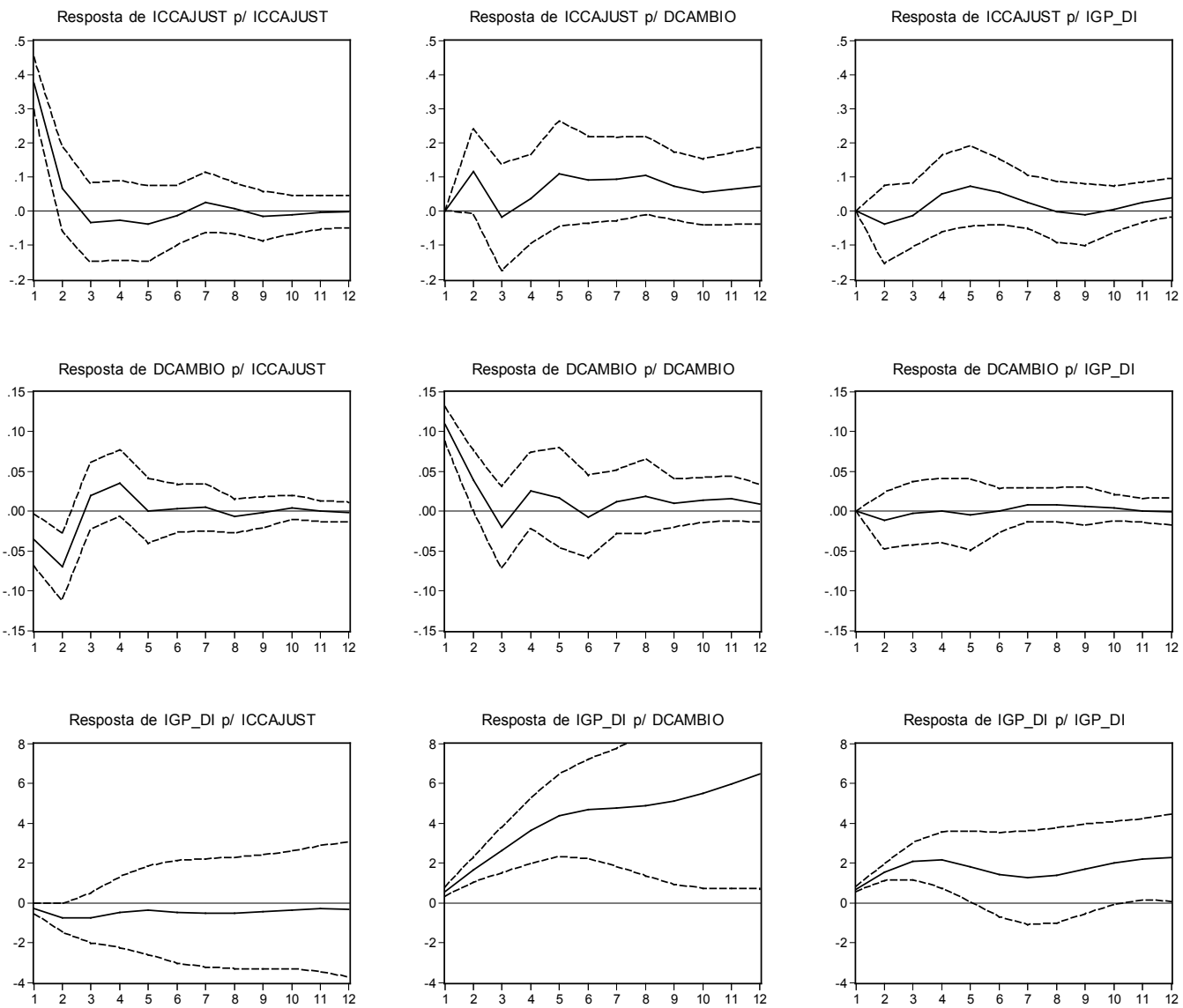

A análise impulso-resposta para os modelos 1 e 2 (vide Figuras 4 e 5) revela que um aumento no ICCajust (aumento da restrição ao movimento de capitais - vide segundo gráfico localizado na primeira linha) tende a provocar uma pequena redução tanto no IGP-DI quanto no IPCA, que tende a perdurar ao longo do tempo (gráficos localizados no canto inferior esquerdo). Também é observado que para ambos os modelos uma desvalorização cambial tende a provocar uma elevação nos índices de preços que não se dissipa (segundo gráfico situado na última linha). Quanto ao impacto originário de um choque externo sobre os valores passados dos próprios índices de preços, é observada a existência de um padrão de regularidade que praticamente não se altera durante os 12 meses (gráfico localizado no canto inferior direito). Os demais casos não apresentam significância estatística. 
FIGURA 5 - FUNCÓES DE RESPOSTA A IMPULSO PARA O VAR - MODELO 2
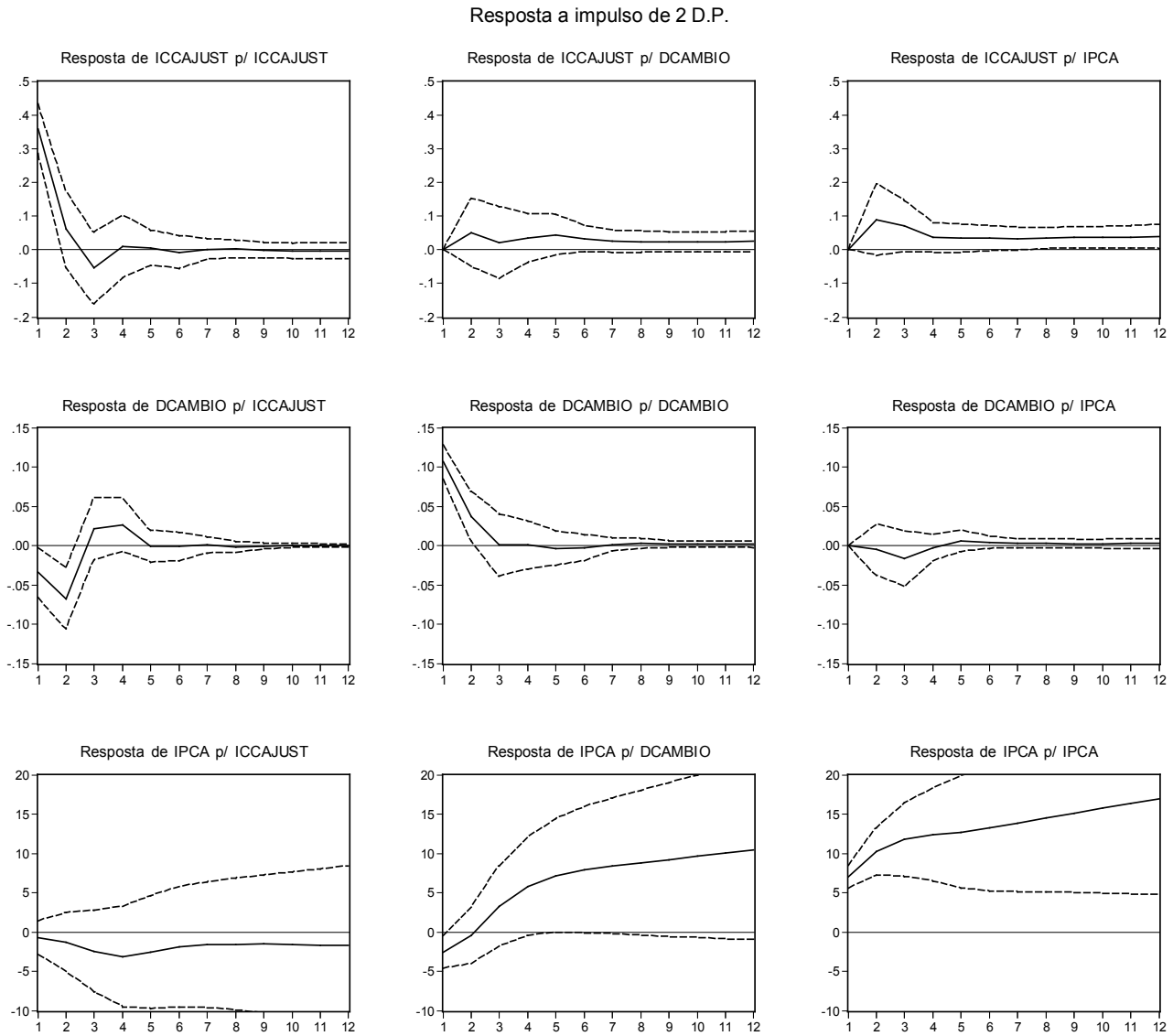

Estes resultados mostram que com os vários choques que atingiram a economia brasileira os controles de capitais se caracterizaram como um instrumento que não pode ser negligenciado na absorção de choques, pois com flutuação cambial e mobilidade de capitais a taxa de câmbio pode ficar sobrecarregada em exercer este papel. Assim, com a introdução de controles de capitais pode-se alcançar a estabilidade da taxa de câmbio e, por conseguinte, atenuar a pressão inflacionária na medida em que este instrumento minimiza o efeito de choques na economia.

\section{CONSIDERAÇÕES FINAIS}

O crescente processo de interdependência das economias devido à aceleração da globalização a partir do final do século XX tem levado a uma revisão na condução das políticas econômicas. Neste sentido, os objetivos da política monetária, em um am- 
biente de abertura financeira, deveriam ser facilitados dado o incentivo que o banco central tem em adotar uma política monetária responsável, buscando, assim, evitar uma possível fuga de capitais. Conforme pôde ser observado no modelo teórico apresentado na seção 1 deste artigo um aumento na liberalização do movimento de capitais também seria capaz de promover um combate efetivo à inflação. Não obstante, o modelo apresentado revela que esse tipo de estratégia não é segura, pois a política de liberalizar a conta de capital pode perder credibilidade. Em uma situação de endividamento, derivado da queda das receitas de senhoriagem, os agentes podem perceber que existe um grande incentivo em adotar controles de capitais no futuro para que o governo eleve suas receitas de senhoriagem e estabilize a razão dívida/PIB. (Bartolini e Drazen, 1997).

As evidências empíricas encontradas para o caso brasileiro mostram que os possíveis benefícios para o controle da inflação não se mostraram efetivos. Pelo contrário, a adoção de controles de capitais está associada a uma atenuação da pressão inflacionária. Em relação ao regime cambial, as evidências apontam para uma relação permanente entre controles de capitais e redução da inflação durante o período em que o câmbio permaneceu flutuante. No caso do período em que o regime de câmbio permaneceu semifixo, esta relação se deu de forma temporária. Portanto, os resultados encontrados neste artigo se aproximam mais daquele obtido no estudo de Rodrik (1998) do que o obtido por Gruben e McLeod (2002).

Além das evidências empíricas a favor da adoção de controle de capitais como mecanismo capaz de atenuar a inflação no caso brasileiro, a liberalização da conta de capitais pode aumentar a volatilidade da atividade econômica real na presença de choques externos, que são exógenos à política econômica doméstica. Em momentos de crises nos mercados financeiros internacionais, os investidores tornam-se mais avessos ao risco e, por conseguinte, vendem títulos adquiridos em países que possuem elevado risco país. (Boyd e Smith, 1997). Como consequiência, esses países sofrem perda de reservas ou desvalorização da taxa de câmbio mesmo que suas políticas monetárias sejam consistentes. O caso brasileiro no período analisado, referente ao regime de câmbio flexível, ilustra bem esse comportamento. Ademais, a literatura mostra evidências (ver Edwards, 2001; e Chinn e Ito, 2002) de que a maior parte dos países emergentes que liberalizou as contas de capitais obteve taxas mais baixas de crescimento econômico e taxas mais altas de instabilidade econômica real.

Em suma, a experiência brasileira mostra que a liberalização da conta de capitais não tem se mostrado capaz de combater a inflação. Ademais, há o risco de haver custos sociais elevados devido ao aumento na volatilidade da atividade econômica real. Isto não significa que o País deva se fechar ao fluxo de capitais e sim que deve existir um 
nível de abertura que permita reduzir os custos da abertura financeira e que permita que os benefícios realmente apareçam. Portanto, uma fonte potencial de pesquisa em adição a este trabalho consiste em avaliar qual o grau de liberalização ótimo para que a sociedade não incorra em custos desnecessários. Em outras palavras, o grau de liberalização da conta de capitais deve ser aquele que minimize de forma simultânea a taxa de inflação e a volatilidade do produto.

\section{REFEREANCLAS BIBLIOGRÁFICAS}

Agénor, P.; Montiel, P. Development macroeconomics. New Jersey: Princeton University Press, 1996.

Barro, R. J.; Gordon, D. Rules, discretion and reputation in a model of monetary policy. Journal of Monetary Economics, 12, North-Holland, p. 101-121, 1983.

Bartolini, L.; Drazen, A. Capital account liberalization as a signal. The American Economic Review, v. 87, n. 1, p. 138-154, March 1997.

Berger, H.; Haan, J. de; Eijffinger, S. C. W. Central bank independence: an update of theory and evidence. Journal of Economic Surveys, v. 15, n. 1, p. 3-40, 2001.

Boyd, J. H.; Smith, B. D. Capital market imperfections, international credit markets and nonconvergence. Journal of Economic Theory, v. 73, n. 2, p. 335-364, 1997.

Calvo, G. A.; Reinhart, C. Fear of floating. The Quarterly Journal of Economics, v. 117, n. 2, p. 379-408, 2002.

Cardoso, E.; Goldfajn, I. Capital flows to Brazil: the endogeneity of capital controls. IMF working paper $n^{0}$ 115, September 1997.

Chinn, M.; Ito, H. Capital account liberalization, institutions and financial development: cross country evidence. NBER, n. 8967, June 2002.

Cukierman, A. Central bank independence and monetary control. The Economic Journal, v. 104, n. 1, p. 437-448, November 1994.

Dornbusch, R. Capital controls: an idea whose time is past. In: Kenen, P. (ed.), Should the IMF pursue capital account convertibility? Princeton Essays in International Finance, n. 207. Princeton University Press, 1998.

Drazen, A. Political economy in macroeconomics. Princeton University Press, 2000.

Edwards, S. Capital mobility and economic performance: are emerging economies different? NBER, n. 8076, January 2001.

Eichengreen, B. International monetary arrangements for the 21st century. Washington, D.C.: The Brookings Institution, 1994. 
Eichengreen, B; Tobin, J.; Wyplosz, C. Two cases for sand in the wheels of international finance. The Economic Journal, v. 105, n. 428, p. 162-172, January 1995.

Enders, W. Applied econometric time series. John Wiley \& Sons, 1995.

Fischer, S. Exchange rate regimes: is the bipolar view correct? Journal of Economic Perspective, XV, p. 3-24, 2001.

Frankel, J. No single currency regime is right for all countries or at all times. NBER Working Paper 7338, 1999.

Friedman, M. The role of monetary policy. American Economic Review, p. 1-17, March 1968.

Gruben, W.; McLeod, D. Capital account liberalization and inflation. Economics Letters, v. 77, n. 2, p. 221-225, 2002.

. Capital account liberalization and disinflation in the 1990s. Federal Reserve Bank of Dallas, Center for Latin American Economics, Working Paper 0101, 2001.

Kim, W. Does capital account liberalization discipline budget deficit? Review of International Economics, v. 11, n. 5, November 2003 (forthcoming).

Kydland, F. E.; Prescott, E. C. Rules rather than discretion: the inconsistency of optimal plans. Journal of Political Economic, v. 85, n. 3, p. 473-492, 1977.

Levy-Yeyati, E.; Sturzenegger, F. Classifying exchange rate regimes: deeds versus words. Universitá Torcuato Di Tella, 2002.

Lourenço, R. F. Regimes cambiais: panorama geral desde as crises nas economias de mercado emergente em meados dos anos 90. Boletim Econômico. Banco de Portugal, p. 129-144, setembro 2004.

Maddala, G. S.; Kim, I. M. Unit roots, cointegration and the structural change. Cambridge University Press, 1998.

Obstfeld, M.; Taylor, A. M. The great depression as a watershed: international capital mobility over the long run. In: Bordo, M.; Goldin, C.; White, E. (eds), The defining moment: the great depression and the American economy in the twentieth century. Chicago: University of Chicago Press, 1998, p. 353-402.

Reinhart, C. M. The mirage of floating exchange rates. The American Economic Review, v. 90, n. 2, p. 65-70, May 2000.

Rodrik, D. Who needs capital account convertibility? In: Kenen, P. (ed.), Should the IMF pursue capital account convertibility? Princeton Essays in International Finance, n. 207. Princeton University Press, 1998.

Rogoff, K. The optimal degree of commitment to an intermediate monetary target. The Quarterly Journal of Economics, p. 1169-1189, November 1985. 
Veríssimo, M. P. Fluxos de portfólio para o Brasil no período 1995-2002: uma análise de vetores auto-regressivos e de causalidade. Instituto de Economia, UFU, Fevereiro 2004.

Vieira, F; Holland, M. Country risk endogeneity, capital flows and capital controls in Brazil. Revista de Economica Politica, v. 23, n. 1 (89), p. 12-38, jan-mar 2003.

Williamson, J. Exchange rate regimes for emerging markets: reviving the intermediate option. Policy Analyses in International Economics 60. Washington, DC: Institute for International Economics, September 2000.

\section{APÊNDICE}

TABELA A.I - TESTE DE RAIZ UNITÁRIA (ADF) - 1995-1998

\begin{tabular}{lcccc}
\hline Séries & Def. & Teste & Valor crítico 1\% & Valor crítico 5\% \\
\hline Câmbio & 9 & 6,264022 & $-2,619851$ & $-1,948686$ \\
D(Câmbio) & 9 & $-5,065477$ & $-4,192337$ & $-3,520787$ \\
ICCajust & 1 & $-3,794924$ & $-2,617364$ & $-1,948313$ \\
IGP-DI & 2 & $-3,510339$ & $-3,577723$ & $-2,925169$ \\
IPCA & 1 & $-3,571980$ & $-3,574446$ & $-2,923780$ \\
\hline
\end{tabular}

Nota: Teste ampliado de Dickey-Fuller (ADF) - o número de defasagens utilizado para cada série foi definido de acordo com o critério de Schwarz (SC). Para as séries Câmbio, ICCajust não foi utilizado constante ou tendência. Para as séries IGP-DI e IPCA foi aplicado constante.

\section{TABELA A.2 - TESTE DE RAIZ UNITÁRIA (PP) - 1995-1998}

\begin{tabular}{lcccc}
\hline Séries & Def. & Teste & Valor crítico 1\% & Valor crítico 5\% \\
\hline Câmbio & 5 & $-2,677445$ & $-4,161144$ & $-3,506374$ \\
D(Câmbio) & 5 & $-7,359814$ & $-3,574446$ & $-2,923780$ \\
ICCajust & 1 & $-6,252428$ & $-3,581152$ & $-2,926622$ \\
IGP-DI & 3 & $-4,178497$ & $-3,5744446$ & $-2,923780$ \\
IPCA & 1 & $-7,305200$ & $-3,574446$ & $-2,923780$ \\
\hline
\end{tabular}

OBS: Def - defasagem aplicada para Bartlett kernel. Para a série Câmbio foram utilizados constante e tendência. Para as séries D(Câmbio), IGP-DI e ICCajust foi utilizado constante.

TABELA A.3 - TESTE DE ESTACIONARIEDADE (KPSS) - 1995-1998

\begin{tabular}{lcccc}
\hline Séries & Def. & Teste & Valor crítico 1\% & Valor crítico 5\% \\
\hline Câmbio & 4 & 0,126387 & 0,216000 & 0,146000 \\
ICCajust & 4 & 0,092494 & 0,739000 & 0,463000 \\
IGP-DI & 5 & 0,224645 & 0,216000 & 0,146000 \\
D(IGP-DI) & 4 & 0,045818 & 0,216000 & 0,146000 \\
IPCA & 5 & 0,232465 & 0,216000 & 0,146000 \\
D(IPCA) & 2 & 0,056371 & 0,216000 & 0,146000 \\
\hline
\end{tabular}

OBS: Def - defasagem aplicada para Bartlett kernel. Para as séries Câmbio, IGP-DI, D(IGP-DI), IPCA e D(IPCA) foram utilizados constante e tendência. Para as séries ICCajust foi utilizado constante. 
TABELA A.4 - TESTES DE RAIZ UNITÁRIA - ADF - 1999-2002

\begin{tabular}{lcccc}
\hline Séries & Def. & Teste & Valor crítico $1 \%$ & Valor crítico $5 \%$ \\
\hline Câmbio & 1 & 1,597364 & $-2,614029$ & $-1,947816$ \\
D(Câmbio) & 0 & $-4,573536$ & $-2,614029$ & $-1,947816$ \\
ICCajust & 0 & $-5,378382$ & $-4,161144$ & $-3,506374$ \\
IGP-DI & 4 & 2,354120 & $-2,614029$ & $-1,947816$ \\
D(IGP-DI) & 2 & $-2,041762$ & $-3,574446$ & $-2,923780$ \\
D(IGP-DI,2) & 1 & $-6,722148$ & $-2,614029$ & $-1,947816$ \\
IPCA & 2 & 3,565686 & $-2,614029$ & $-1,947816$ \\
D(IPCA) & 2 & 0,440991 & $-2,614029$ & $-1,947816$ \\
D(IPCA,2) & 1 & $-8,346750$ & $-2,614029$ & $-1,947816$ \\
\hline
\end{tabular}

Nota: Teste ampliado de Dickey-Fuller (ADF) - o número de defasagens utilizado para cada série foi definido de acordo com o critério de Schwarz (SC). Para a série ICCajust foi usado constante e tendência. Para as demais séries não foi utilizado constante ou tendência.

TABELA A.5 - TESTE DE RAIZ UNITÁRIA PP - 1999-2002

\begin{tabular}{lcccc}
\hline Séries & Def. & Teste & Valor crítico 1\% & Valor crítico 5\% \\
\hline Câmbio & 0 & 2,540008 & $-2,614029$ & $-1,947816$ \\
D(Câmbio) & 2 & $-4,534313$ & $-2,614029$ & $-1,947816$ \\
ICCajust & 1 & $-5,364838$ & $-4,161144$ & $-3,506374$ \\
IGP-DI & 3 & 1,885601 & $-4,161144$ & $-3,506374$ \\
D(IGP-DI) & 5 & $-0,820038$ & $-2,614029$ & $-1,947816$ \\
D(IGP-DI,2) & 23 & $-2,167065$ & $-2,614029$ & $-1,947816$ \\
IPCA & 4 & 3,185425 & $-4,161144$ & $-3,506374$ \\
D(IPCA) & 2 & $-2,862222$ & $-3,574446$ & $-2,923780$ \\
D(IPCA,2) & 15 & $-8,771302$ & $-2,614029$ & $-1,947816$ \\
\hline
\end{tabular}

OBS: Def - defasagem aplicada para Bartlett kernel. Não foi utilizado constante ou tendência para as séries Câmbio, D(Câmbio), D(IGP-DI), D(IGP-DI,2) e D(IPCA,2). Para as séries ICCajust, IGP-DI e IPCA foram utilizados constante e tendência. Para as séries D(Câmbio), ICCajust e D(IPCA) foi utilizado constante.

TABELA A.6 - TESTE DE ESTACIONARIEDADE (KPSS) - 1999-2002

\begin{tabular}{lcccc}
\hline Séries & Def. & Teste & Valor crítico 1\% & Valor crítico 5\% \\
\hline Câmbio & 5 & 0,164786 & 0,216000 & 0,146000 \\
ICCajust & 3 & 0,149252 & 0,216000 & 0,146000 \\
IGP-DI & 4 & 0,141049 & 0,216000 & 0,146000 \\
IPCA & 4 & 0,208559 & 0,216000 & 0,146000 \\
\hline
\end{tabular}

OBS: Def - defasagem aplicada para Bartlett kernel. Para as séries Câmbio, ICCajust, IGP-DI, IPCA foram utilizados constante e tendência. 
FIGURA A.2.1 - CORRELOGRAMA DAS SÉRIES - 1995-1998
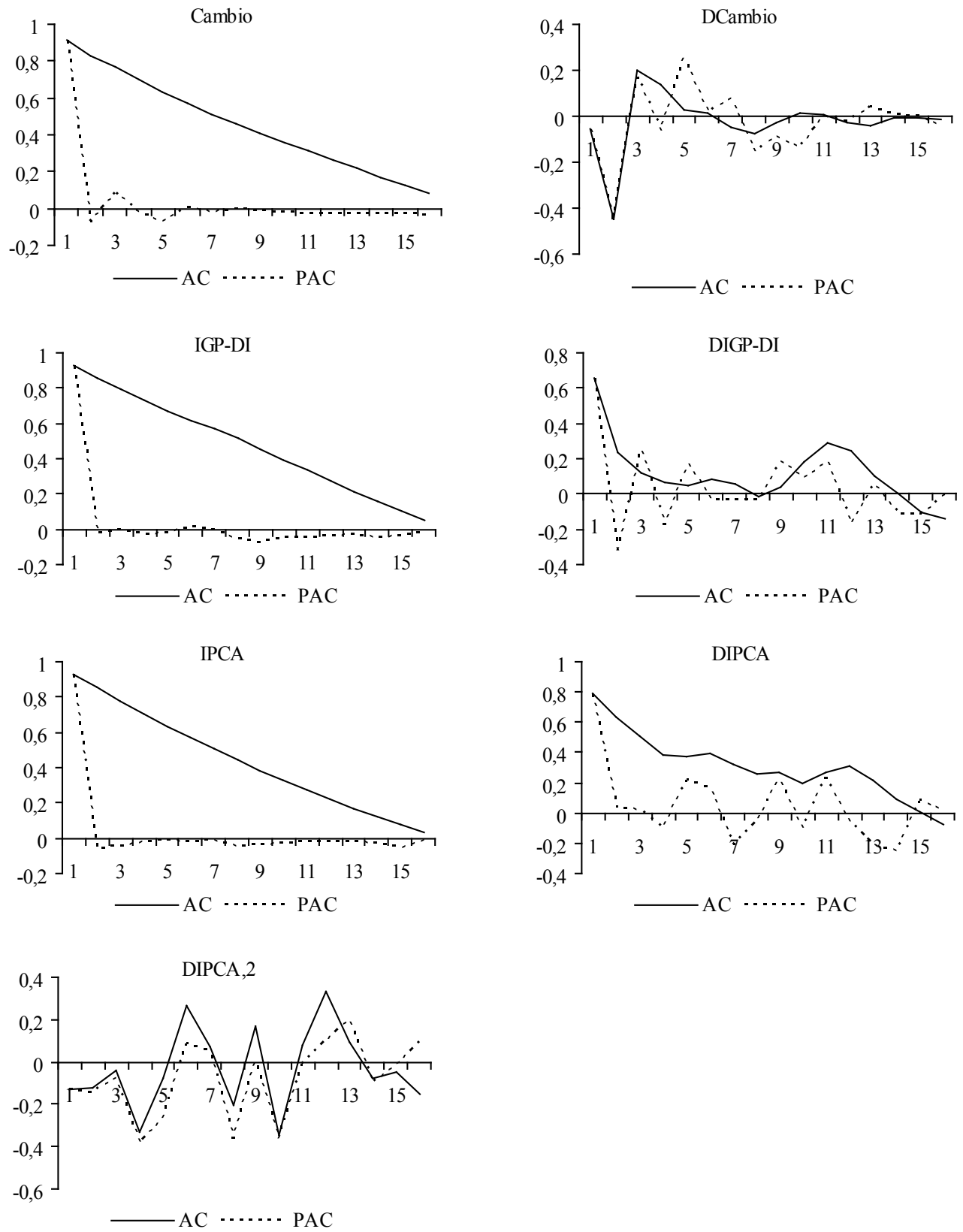

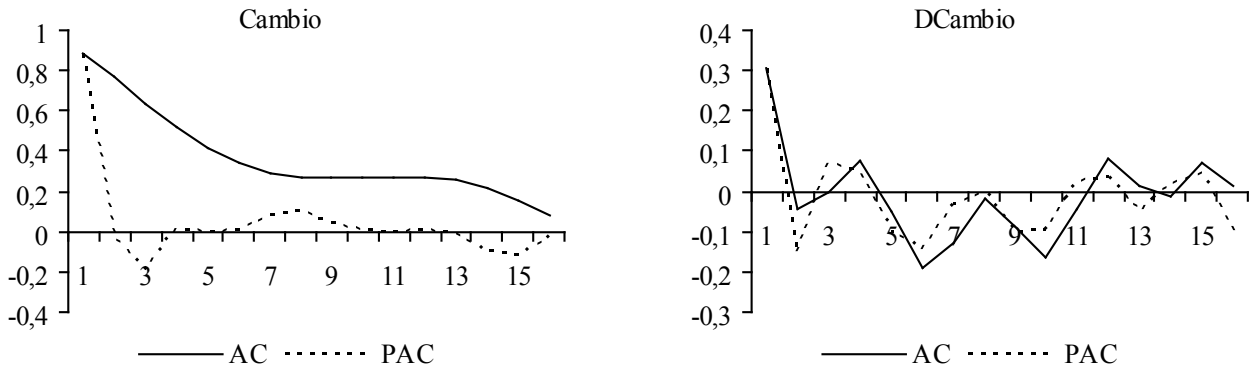

TABELA A.7 - CRITÉRIO DE AIC, SIC E HQ PARA O VAR - (1995-1998)

\begin{tabular}{|c|c|c|c|c|c|c|}
\hline \multirow[b]{2}{*}{ Def. } & \multicolumn{6}{|c|}{ Modelo 1} \\
\hline & \multicolumn{3}{|c|}{ com constante } & \multicolumn{3}{|c|}{ sem constante } \\
\hline & $\mathrm{AIC}$ & $\mathrm{SIC}$ & $\mathrm{HQ}$ & $\mathrm{AIC}$ & $\mathrm{SIC}$ & $\mathrm{HQ}$ \\
\hline 0 & $-4,001624$ & $-3,878750$ & $-3,956312$ & & & \\
\hline 1 & $-4,522290$ & $-4,030792^{*}$ & $-4,341040$ & $-3,734231$ & $-3,365608$ & $-3,598294$ \\
\hline 2 & $-4,569640$ & $-3,709519$ & $-4,252454$ & $-4,280797$ & $-3,543551$ & $-4,008923$ \\
\hline 3 & $-4,982117^{*}$ & $-3,753373$ & $-4,528994^{*}$ & $-4,863459^{*}$ & $-3,757589^{*}$ & $-4,455648^{*}$ \\
\hline 4 & $-4,962765$ & $-3,365398$ & $-4,373706$ & $-4,814723$ & $-3,340230$ & $-4,270976$ \\
\hline & \multicolumn{6}{|c|}{ Modelo 2} \\
\hline Def. & \multicolumn{3}{|c|}{ com constante } & \multicolumn{3}{|c|}{ sem constante } \\
\hline & AIC & SIC & $\mathrm{HQ}$ & AIC & SIC & $\mathrm{HQ}$ \\
\hline 0 & $-0,323011$ & $-0,198892$ & $-0,277517$ & & & \\
\hline 1 & $-0,771438^{*}$ & $-0,274961^{*}$ & $-0,589460^{*}$ & $-0,551854^{*}$ & $-0,179496^{*}$ & $-0,415370^{*}$ \\
\hline 2 & $-0,561074$ & 0,307760 & $-0,242612$ & $-0,319538$ & 0,425178 & $-0,046570$ \\
\hline 3 & $-0,479185$ & 0,762008 & $-0,024239$ & $-0,310536$ & 0,806537 & 0,098915 \\
\hline 4 & $-0,606200$ & 1,007350 & $-0,014770$ & $-0,474711$ & 1,014720 & 0,071225 \\
\hline 5 & $-0,542061$ & 1,443847 & 0,185853 & $-0,334193$ & 1,527596 & 0,348226 \\
\hline
\end{tabular}

Nota: * indica a ordem do VAR selecionado pelo critério.

TABELA A.8 - CRITÉRIO DE AIC, SIC E HQ PARA O VAR - (1999-2002)

\begin{tabular}{|c|c|c|c|c|c|c|}
\hline \multirow[b]{2}{*}{ Def. } & \multicolumn{6}{|c|}{ Modelo 1} \\
\hline & \multicolumn{3}{|c|}{ com constante } & \multicolumn{3}{|c|}{ sem constante } \\
\hline & $\mathrm{AIC}$ & SIC & $\mathrm{HQ}$ & $\mathrm{AIC}$ & SIC & $\mathrm{HQ}$ \\
\hline 0 & 9,157012 & 9,273962 & 9,201207 & & & \\
\hline 1 & 3,487811 & 3,955611 & 3,664593 & 3,753261 & 4,104111 & 3,885848 \\
\hline 2 & 2,198322 & $3,016973^{*}$ & 2,507691 & 2,340915 & $3,042615^{*}$ & 2,606088 \\
\hline 3 & $1,928228^{*}$ & 3,097728 & $2,370184^{*}$ & 2,074810 & 3,127361 & $2,472571^{*}$ \\
\hline \multirow[t]{2}{*}{4} & 1,971727 & 3,492078 & 2,546270 & $2,033776^{*}$ & 3,437177 & 2,564123 \\
\hline & \multicolumn{6}{|c|}{ Modelo 2} \\
\hline Def. & \multicolumn{3}{|c|}{ com constante } & \multicolumn{3}{|c|}{ sem constante } \\
\hline & $\mathrm{AIC}$ & SIC & $\mathrm{HQ}$ & $\mathrm{AIC}$ & $\mathrm{SIC}$ & $\mathrm{HQ}$ \\
\hline 0 & 12,37548 & 12,49243 & 12,41968 & & & \\
\hline 1 & 6,723506 & 7,191306 & 6,900288 & 7,059742 & 7,410592 & 7,192329 \\
\hline 2 & $6,290628^{*}$ & $7,109278^{*}$ & $6,599997^{*}$ & $6,399924^{*}$ & $7,101625^{*}$ & $6,665098^{*}$ \\
\hline 3 & 6,356615 & 7,526115 & 6,798571 & 6,515870 & 7,568420 & 6,913630 \\
\hline 4 & 6,388377 & 7,908728 & 6,962920 & 6,447429 & 7,850830 & 6,977776 \\
\hline
\end{tabular}

Nota: * indica a ordem do VAR selecionado pelo critério. 
TABELA A.9 - TESTE DE PRECEDÊNCIA TEMPORAL DE GRANGER (19951998)

\begin{tabular}{lccc}
\hline Modelo 1 - VAR(3) & & & \\
\hline Hipótese nula: & Obs & Estatística-F & Probabilidade \\
\hline DCAMBIO não Granger causa ICCAJUST & 44 & 0,42538 & 0,73595 \\
ICCAJUST não Granger causa DCAMBIO & & 1,50275 & 0,22984 \\
\hline DIGP_DI não Granger causa ICCAJUST & 44 & 0,16425 & 0,91976 \\
ICCAJUST não Granger causa DIGP_DI & & 0,79144 & 0,50645 \\
\hline DIGP_DI não Granger causa DCAMBIO & 45 & 1,28145 & 0,29461 \\
DCAMBIO não Granger causa DIGP_DI & & 4,81447 & 0,00614 \\
\hline Modelo 2 - VAR(1) & 46 & & 0,04027 \\
\hline DCAMBIO não Granger causa ICCAJUST & & 0,61450 & 0,84190 \\
ICCAJUST não Granger causa DCAMBIO & 46 & 0,30994 & 0,43739 \\
\hline DIPCA,2 não Granger causa ICCAJUST & & 3,39949 & 0,07211 \\
ICCAJUST não Granger causa DIPCA,2 & 47 & 2,84611 & 0,09867 \\
\hline DIPCA,2 não Granger causa DCAMBIO & & 3,28100 & 0,07692 \\
DCAMBIO não Granger causa DIPCA,2 & & & \\
\hline
\end{tabular}

TABELA A.10 - TESTE DE PRECEDÊNCIA TEMPORAL DE GRANGER (19992002)

\begin{tabular}{lccc}
\hline Modelo 1 - VAR(3) & & & \\
\hline Hipótese nula: & Obs & Estatística-F & Probabilidade \\
\hline DCAMBIO não Granger causa ICCAJUST & 48 & 2,18833 & 0,10398 \\
ICCAJUST não Granger causa DCAMBIO & & 6,19757 & 0,00143 \\
\hline IGP-DI não Granger causa ICCAJUST & 48 & 4,01512 & 0,01356 \\
ICCAJUST não Granger causa IGP-DI & & 4,84588 & 0,00561 \\
\hline IGP-DI não Granger causa DCAMBIO & 48 & 0,49041 & 0,69087 \\
DCAMBIO não Granger causa IGP-DI & & 2,74120 & 0,05544 \\
\hline Modelo 2 - VAR(2) & 48 & & \\
\hline DCAMBIO não Granger causa ICCAJUST & & 9,98608 & 0,06105 \\
ICCAJUST não Granger causa DCAMBIO & 48 & 7,49318 & 0,00038 \\
\hline IPCA não Granger causa ICCAJUST & & 0,02033 & 0,00161 \\
ICCAJUST não Granger causa IPCA & 48 & 0,35650 & 0,70217 \\
\hline IPCA não Granger causa DCAMBIO & & 6,69858 & 0,00293 \\
DCAMBIO não Granger causa IPCA & & & \\
\hline
\end{tabular}

